OPEN ACCESS

Edited by:

Maria Cristina D'Adamo,

University of Malta, Malta

Reviewed by:

Mario Kassmann,

Charité - Universitätsmedizin Berlin,

Germany

Candice Contet,

Scripps Research Institute,

United States

*Correspondence:

Marcel P. Bruchez

bruchez@cmu.edu

Received: 05 August 2017 Accepted: 12 October 2017 Published: 31 October 2017

Citation:

Pratt $C P$, Kuljis DA, Homanics GE, He J, Kolodieznyi D, Dudem S, Hollywood MA, Barth AL and Bruchez MP (2017) Tagging of Endogenous BK Channels with a Fluorogen-Activating Peptide Reveals $\beta 4$-Mediated Control of Channel Clustering in Cerebellum. Front. Cell. Neurosci. 11:337. doi: 10.3389/fncel.2017.00337

\section{Tagging of Endogenous BK Channels with a Fluorogen-Activating Peptide Reveals $\beta 4$-Mediated Control of Channel Clustering in Cerebellum}

\author{
Christopher P. Pratt ${ }^{1,2,3}$, Dika A. Kuljis' ${ }^{1}$, Gregg E. Homanics ${ }^{4,5,6}$, Jianjun $\mathrm{He}^{2,7}$, \\ Dmytro Kolodieznyi ${ }^{2,7}$, Srikanth Dudem ${ }^{8}$, Mark A. Hollywood ${ }^{8}$, Alison L. Barth ${ }^{1,3}$ and \\ Marcel P. Bruchez $1,2,7 *$

\begin{abstract}
${ }^{1}$ Department of Biological Sciences, Carnegie Mellon University, Pittsburgh, PA, United States, ${ }^{2}$ Molecular Biosensor and Imaging Center, Carnegie Mellon University, Pittsburgh, PA, United States, ${ }^{3}$ Center for the Neural Basis of Cognition, Carnegie Mellon University, Pittsburgh, PA, United States, ${ }^{4}$ Department of Anesthesiology, University of Pittsburgh, Pittsburgh, PA, United States, ${ }^{5}$ Department of Neurobiology, University of Pittsburgh, Pittsburgh, PA, United States, ${ }^{6}$ Department of Pharmacology and Chemical Biology, University of Pittsburgh, Pittsburgh, PA, United States, ${ }^{7}$ Department of Chemistry, Carnegie Mellon University, Pittsburgh, PA, United States, ${ }^{8}$ Smooth Muscle Research Centre, Dundalk Institute
\end{abstract} \\ of Technology, Dundalk, Ireland
}

BK channels are critical regulators of neuronal activity, controlling firing, neurotransmitter release, cerebellar function, and BK channel mutations have been linked to seizure disorders. Modulation of BK channel gating is well characterized, regulated by accessory subunit interactions, intracellular signaling pathways, and membrane potential. In contrast, the role of intracellular trafficking mechanisms in controlling BK channel function, especially in live cells, has been less studied. Fluorogen-activating peptides (FAPs) are well-suited for trafficking and physiological studies due to the binding of malachite green (MG)-based dyes with sub-nanomolar affinity to the FAP, resulting in bright, photostable, far-red fluorescence. Cell-excluded MG dyes enable the selective tagging of surface protein and tracking through endocytic pathways. We used CRISPR to insert the FAP at the extracellular N-terminus of BKa in the first exon of its native locus, enabling regulation by the native promoter elements and tag incorporation into multiple splice isoforms. Motor coordination was found to be normal; however, BK channel expression seems to be reduced in some locations. Alternate start site selection or post-translational proteolytic processing resulted in incomplete FAP tagging of the BK $\alpha$ proteins in brain tissues. In Purkinje cell somata, FAP revealed BK channel clustering previously only observed by electron microscopy. Measurement of these clusters in $\beta 4^{+/-}$and $\beta 4^{-/-}$mice showed that puncta number and cluster fluorescence intensity on the soma are reduced in $\beta 4^{-/-}$knockout animals. This novel mouse line provides a versatile fluorescent platform for studying endogenous BK channels in living and fixed tissues. Future studies could apply this line to ex vivo neuronal cultures to study live-cell channel trafficking.

Keywords: BK channels, CRISPR/Cas9, fluorogen-activating peptides, knock-in, Purkinje cells, fluorescent dyes, trafficking 


\section{INTRODUCTION}

The large conductance voltage and calcium-activated potassium channel (BK, MaxiK, Slo1, gene name: Kcnma1) is activated by membrane depolarization and elevated intracellular calcium (Toro et al., 1998; Vergara et al., 1998). BK channels are broadly expressed in many tissues including the central nervous system (Tseng-Crank et al., 1994). In the brain, they regulate neurotransmitter release and control neuronal spike rates ( $\mathrm{Hu}$ et al., 2001; Gu et al., 2007; Contet et al., 2016; Griguoli et al., 2016). The functional channel is formed by a tetramer of $\alpha$ subunits (Toro et al., 1998); alternative splicing produces channels with varied gating properties (Shipston et al., 1999; Soom et al., 2008; Poulsen et al., 2009), responses to intracellular signaling pathways (Tian et al., 2003; van Welie and du Lac, 2011; Toro et al., 2013), and trafficking (Ma et al., 2007; Chiu et al., 2010). BK $\alpha$ knockout mice most starkly show cerebellar ataxia with deficits in coordination, reflex, and spatial learning (Sausbier et al., 2004). In humans, gain or loss of $\mathrm{BK} \alpha$ function precipitates epilepsy, developmental delay, and movement disorders (Du et al., 2005; Zhang Z.-B. et al., 2015; Tabarki et al., 2016).

The contribution of a channel to cellular activity depends on its ion flux, which is controlled by the number of channels at the plasma membrane (PM) and their open probability. Mounting evidence suggests that control of trafficking may be a key regulator of BK activity (Toro et al., 2006; Kim E.Y. et al., 2007; Ma et al., 2007; Zarei et al., 2007; Shruti et al., 2012). The relatively low abundance of BK coupled with its high conductance (Kang et al., 1996; Vergara et al., 1998) suggests that modest changes in surface levels could have profound effects on cell activity (Ly et al., 2011). Several kinases acting on BK channels (Wang, 2008; van Welie and du Lac, 2011; Kyle and Braun, 2014) have been shown to affect trafficking of other potassium channels (Connors et al., 2008; Gabriel et al., 2012) and could thus play a role for $\mathrm{BK}$ as a long-term form of regulation. Recent work from our lab showed that extended elevation of cyclic AMP with forskolin suppresses surface $\mathrm{BK} \alpha$ abundance when expressed alone in heterologous cells (Pratt et al., 2015); a mechanism which could affect BK currents in learning (Nelson et al., 2003; Matthews et al., 2008; Matthews and Disterhoft, 2009).

Up to four $\beta$ subunits and a single $\gamma$ subunit assemble with the $\alpha$ tetramer to modify channels' biophysical properties and trafficking (Behrens et al., 2000; Brenner et al., 2000; GonzalezPerez et al., 2014, 2015). The brain-enriched $\beta 4$ subunit produces BK channels that are resistant to iberiotoxin and charybdotoxin, have slower activation and deactivation rates, and reduced response to calcium (Behrens et al., 2000; Brenner et al., 2000; Lippiat et al., 2003). An endoplasmic reticulum (ER)-retention motif at the C-terminus of $\beta 4$ regulates the forward trafficking of whole channels in heterologous cells (Shruti et al., 2012), though in the brain this effect appears to be dependent on cell type. CA3 and neocortical pyramidal cells do not exhibit detectable $\mathrm{BK} \alpha \beta 4$ currents, despite robust expression (Shruti et al., 2012; Cox et al., 2014); however, other neuron types do exhibit these currents, often with $\beta 4$ localized to specific neuronal compartments (Dopico et al., 1999; Hu et al., 2001;
Brenner et al., 2005; Wynne et al., 2009; Martire et al., 2010). In cerebellar Purkinje cells (PCs), the majority of somatic BK current is fluxed through $\beta 4$-containing channels (Benton et al., 2013), suggesting that $\beta 4$ may influence BK channel localization and trafficking.

In order to faithfully measure the localization of endogenous BK channels, we generated a gene-targeted mouse in which hemagglutinin (HA) and FAP tag were inserted into at the endogenous $\mathrm{BK} \alpha$ locus at exon 1, which is incorporated into all known functional BK $\alpha$ (Erxleben, 2002; Poulsen et al., 2011; Sakai et al., 2011). FAP-BK $\alpha$ channels exhibit similar voltage and calcium responses as untagged $\mathrm{BK} \alpha$. FAP-BK $\alpha$ mice exhibit neither the motor deficits nor aberrant PC pacemaking observed in $\mathrm{BK} \alpha$ knockout mice. In the presence of malachite green (MG)-based dyes, FAP produces a bright and highly photostable far-red fluorophore, enabling enhanced tissue penetration and highly stable emission for single-molecule applications. FAP successfully labeled BK channels. While not all $\alpha$ subunits were tagged, likely due to alternate start site selection or posttranslational proteolytic processing, tagged and untagged $\alpha$ subunits coassemble into channels. FAP expression in the brain, identified by HA immunostaining and FAP-MG labeling, is representative of native $\mathrm{BK} \alpha$. Using this model, we found that $\beta 4$ subunit expression is associated with increased clustering of PC somatic BK channels; this characterizes a role for $\beta 4$ subunit in regulating channel localization beyond ER retention. This mouse model will facilitate future studies of BK channel localization, dynamic trafficking, and single molecule characterization in dissociated neurons and slice cultures.

\section{MATERIALS AND METHODS}

\section{Dyes and FAP}

Cell-excluded MG-BTau was prepared as described previously (Yan et al., 2015). MG-TCarb, a dye optimized for fixed tissue use and putatively cell excluded, was synthesized using an MG-EDA precursor (Szent-Gyorgyi et al., 2007). The precursor dye was functionalized with a tripod linker containing three tert-butyl ester functional groups, which were then hydrolyzed to carboxylic acid. Detailed synthesis details can be found in the Supplementary Information. 100-300 $\mu \mathrm{M}$ working stocks $(1000 \times)$ were prepared by dissolving MG-BTau in PBS; MGTCarb was dissolved in $95 \%$ ethanol to maximize dye stability and solubility. All experiments used the $\mathrm{dL} 5^{* *}$ variety of FAP (Szent-Gyorgyi et al., 2013).

\section{Cell Culture and Transfection}

HEK cells were grown in DMEM/MEM supplemented with $10 \%$ heat-inactivated FBS (fetal bovine serum) and $1 \%$ penicillin/streptomycin antibiotic at $37^{\circ} \mathrm{C}$ in a humidified incubator with $5 \% \mathrm{CO}_{2}$. Wild-type (WT) murine $\mathrm{BK} \alpha$ and FAP-BK $\alpha$ encoding plasmid DNAs (accession No. NM_010610.2, available on Addgene, IDs 73212 and 73213) (Pratt et al., 2015) were introduced into HEK cells using the calcium phosphate transfection method. HEK cells were used for electrophysiological recordings $24-48 \mathrm{~h}$ after transfection. 


\section{Establishment of FAP-BK $\alpha$ Mouse Line}

A targeting plasmid, Cas9 RNA-guided nuclease, and two sgRNAs were used to replace $195 \mathrm{bp}$ of Kcnmal exon 1 with an 855 bp insertion containing an N-terminal HA epitope (YPYDVPDYA) and dL5** FAP (Szent-Gyorgyi et al., 2013) fused immediately $5^{\prime}$ of the MDAL start site. An Igк signal sequence was also used to ensure correct topology; addition of a signal sequence was shown to not disrupt $\mathrm{BK} \alpha$ function (Wallner et al., 1996). A cocktail containing sgRNA (12.5$60 \mathrm{ng} / \mu \mathrm{L})$, Cas 9 mRNA (30-110 ng/ $\mu \mathrm{L}$ ), and undigested circular repair plasmid (100-360 ng/ $/ \mathrm{L})$ were injected into fertilized C57BL/6J one-cell embryos. A total of 109 founder mice were produced from injected embryos and 102 were analyzed for gene targeting. PCR at the $3^{\prime}$-end showed insertion, but PCR using primers flanking the $5^{\prime}$-end locus was unsuccessful (not shown). Of the screened pups, one founder No. 4159 was identified and mated to C57BL/6J females to establish the FAP$\mathrm{BK} \alpha$ line. This founder mouse was derived from embryos injected cytoplasmically with $50 \mathrm{ng} / \mu \mathrm{L}$ each sgRNA, $100 \mathrm{ng} / \mu \mathrm{L}$ Cas9 mRNA, and $200 \mathrm{ng} / \mu \mathrm{L}$ targeting plasmid. Screening for FAP-BK $\alpha$-positive mice was initially performed using a primer set (F2R8, see Supplementary Material, Supplementary Table S1 for all primer details) to amplify a 388 bp product if transgene is present. Genotyping was performed with forward primer 5'-GCAACATGGCTGTTGATGGGTGTTC-3' and reverse primer $5^{\prime}$-GTCACCGGTATGATGAGCGCATCC$3^{\prime}$ cycled using $30 \mathrm{~s}$ annealing at $60^{\circ} \mathrm{C}$ for $20-25$ cycles to produce a $309 \mathrm{bp}$ band for the WT allele and a $969 \mathrm{bp}$ band for the transgene. FAP-BKa mice were bred to generate $\mathrm{WT}$, heterozygous (Het), and homozygous (Hom) littermates; zygosity was determined by genotyping. Southern blotting was performed with $\mathrm{BK} \alpha$ external to the targeting construct with digestion with EcoRV and BglII. See Supplementary Material for more detailed information. FAP-BK $\alpha$ transgenic mice will be available from The Jackson Laboratory (JAX Strain \# 031059).

BK $\beta 4$ knockout mice were maintained in a C57BL/6J background (Brenner et al., 2005; Shruti et al., 2012). $\beta 4$ KO mice were crossed with FAP-BK $\alpha$ mice to generate double Het mice and FAP-BK $\alpha$ Hom, $\beta 4 \mathrm{KO}$ mice. For FAP-BK $\alpha / \beta 4 \mathrm{KO}$ experiments, FAP-BK $\alpha$ Hom $/ \beta 4$ KO males were crossed with $\beta 4$ Het females to generate FAP-BK $\alpha$ Het offspring with $\beta 4$ Het or KO genotypes.

\section{Electrophysiology \\ Characterization of FAP-BKo}

Experiments were performed at $37^{\circ} \mathrm{C}$ in $140 \mathrm{mM}$ symmetrical $\mathrm{K}^{+}$solutions which contained $140 \mathrm{mM} \mathrm{KCl}, 10 \mathrm{mM}$ glucose, $10 \mathrm{mM}$ HEPES, and either $1 \mathrm{mM}$ EGTA (for free $\left[\mathrm{Ca}^{2+}\right]$ ranging $100-300 \mathrm{nM}$ ) or $1 \mathrm{mM}$ EDTA (for free $\left[\mathrm{Ca}^{2+}\right] 1-10 \mathrm{nM}$ ) and $\mathrm{Ca}^{2+}$ concentrations were confirmed with a $\mathrm{Ca}^{2+}$ electrode. All solutions were made up in double distilled, deionized, filtered water from a MilliQ water purification system. The pipette solution contained $100 \mathrm{nM}$ free $\mathrm{Ca}^{2+}$ as per previous studies (Roy et al., 2012, 2014).

Electrodes were pulled from Corning borosilicate glass $(1.5 \mathrm{~mm}$ OD $\times 0.86 \mathrm{~mm}$ ID) using a Sutter P-97 pipette puller and were fire polished using a Narishige MF 83 microforge. Pipettes had a resistance of 2-5 $\mathrm{M} \Omega$ when filled with recording solutions and series resistance was compensated by up to $80 \%$. Standard single-channel patch clamp recording methods were used in the inside-out patch conformation. Voltage clamp commands were delivered via an Axopatch 200A patch clamp amplifier (Axon Instruments) connected to a Digidata 1322A AD/DA converter (Axon Instruments) interfaced to a computer running pClamp software (Axon Instruments). Data were acquired at $100 \mathrm{KHz}$ and filtered at $2 \mathrm{KHz}$. Patches were held at either $-60 \mathrm{mV}$ or $-100 \mathrm{mV}$ and depolarized in $20 \mathrm{mV}$ increments to $200 \mathrm{mV}$. Residual capacitance and leakage currents were subtracted using either a P/4 protocol, or offline by manual leak subtraction.

\section{Acute Slice Recordings}

Three to four week old animals (FAP-BK $\alpha$ heterozygous, homozygous, and WT littermates) were anesthetized with isoflurane, decapitated, and whole-brains dissected in ice cold artificial cerebrospinal fluid (ACSF) with the following composition (millimolar): $119 \mathrm{NaCl}, 2.5 \mathrm{KCl}, 2.5 \mathrm{CaCl}_{2}, 1.3$ $\mathrm{MgSO}_{4}, 1 \mathrm{NaH}_{2} \mathrm{PO}_{4}, 26.2 \mathrm{NaHCO}_{3}$, and 11 glucose equilibrated with $95 \% \mathrm{O}_{2} / 5 \% \mathrm{CO}_{2}$. Sagittal slices $(350 \mu \mathrm{m})$ were sectioned in ice-cold ACSF using a vibratome (Leica VT1200; Buffalo Grove, IL, United States), then transferred to room temperature ACSF for 30-60 min before mounting on a fixed-stage Olympus microscope equipped for differential interference contrast microscopy. Slices were continually perfused with aerated ACSF using a gravity perfusion system. Cell-attached recordings were acquired using the Multiclamp 700B (Molecular Devices) amplifier and National Instruments acquisition interface. Data were filtered at $3 \mathrm{kHz}$, digitized at $10 \mathrm{kHz}$, and collected by Igor Pro 6.0 (Wavemetrics). Loose-patch recordings were performed in voltage-clamp mode using glass electrodes (7-10 M $\Omega$ ) filled with ACSF. Baseline spontaneous action potential frequency was collected over 5 min in ACSF containing 1\% dimethyl sulfoxide. Baseline spike rates were compared among genotypes using one-way ANOVA with Tukey's multiple comparison test $(P<0.05)$.

Primary somatosensory cortical neuron recordings were performed using coronal brain slices harvested from WT and FAP-BK $\alpha$ expressing neonates (P12-15). Layer 2 pyramidal neurons were targeted visually and whole-cell recordings were performed using glass electrodes filled with K-gluconate internal solution, which was composed of the following (millimolar): $125 \mathrm{~K}$-gluconate, $2 \mathrm{KCl}, 0.5 \mathrm{EGTA}, 10 \mathrm{HEPES}, 4 \mathrm{MgATP}, 0.3$ GTP. Internal solution also contained Alexa488, which was used to fill recorded cells in order to identify pyramidal neuron morphology. Once a G $\Omega$ seal was formed and negative pressure applied to rupture the membrane and enter whole-cell recording conditions, the cell was held in current clamp mode for $5 \mathrm{~min}$ before input resistance $\left(R_{\mathrm{IN}}\right)$ and resting membrane potential readings were collected. To examine action potential waveform, rheobase current (minimal current to elicit one action potential) was injected for each cell examined. After collecting baseline data, MG-Btau (300 nM, $\mathrm{H}_{2} \mathrm{O}$ vehicle) was applied for $10 \mathrm{~min}$, after which resting membrane parameters and action potential 
waveforms were re-examined. Finally, slices were washed for 2030 min with ACSF and cells tested for washout effects. Effects of genotype and MG-Btau on resting membrane potential, input resistance, and rheobase current were tested using a repeated measures two-way ANOVA $(P<0.05)$.

\section{Curve Fitting and Statistics}

Under our recording conditions at $37^{\circ} \mathrm{C}$, the tail currents in $100 \mathrm{nM} \mathrm{Ca}^{2+}$ deactivated so rapidly that we were unable to accurately determine the activation of the channels as noted previously (Webb et al., 2015). Consequently, conductance $(G)$ was derived from steady-state currents according to Ohm's law

$$
G=\frac{1}{V-E_{K}},
$$

where $E_{K}=0 \mathrm{mV}$ in symmetrical $\left[\mathrm{K}^{+}\right]$. Summary data were expressed as the mean \pm SEM. $G-V$ relationships were fitted with the Boltzmann equation

$$
\frac{G}{G_{\max }}=\frac{1}{1+e^{\frac{V_{m}-V_{1 / 2}}{S}}},
$$

where $V_{1 / 2}$ is the voltage of half-maximum activation, $S$ is the slope of the curve, $\mathrm{V}_{\mathrm{m}}$ the test potential, $G$ the conductance, and $G_{\max }$ the maximal conductance. Data from each patch were normalized to the peak conductance measured in $10 \mu \mathrm{M} \mathrm{Ca}^{2+}$ to obtain $G_{\max }$. All curves were constrained to the $G_{\max }$ value obtained in $10 \mu \mathrm{M} \mathrm{Ca}^{2+}$.

\section{Motor Testing}

Balance and motor coordination were tested in juvenile littermate mice (5-7 weeks, four to six males, and four to six females) of each genotype on the accelerating rotarod (Med Associates, Inc., St. Albans, VT, United States). For each trial, the rotational speed increased linearly from 6 to 60 RPM over the first $300 \mathrm{~s}$, then continued at 60 RPM for the subsequent $200 \mathrm{~s}$ after which the trial was terminated. Mice were tested with five trials per day over five consecutive days at mid-day. A repeated measures twoway ANOVA was used to test for effects of genotype by sex on rotarod latency to fall over all trials $(P<0.05)$, as well as effects of genotype and sex on average latency to fall on the last day of testing. If a significant effect was detected, Tukey's multiple comparison test was used to identify significant group differences $(P<0.05)$.

Gaits for five to six littermate mice $(n=17$ animals, WT: $4 \times$ F, $2 \times \mathrm{M}$; Het $5 \times$ F, $1 \times \mathrm{M}$; Hom $5 \times 4,1 \times$ M. Individual litters were sex-matched) were examined by dipping hindpaws and forepaws in blue and yellow watercolor, respectively (Royal Talens, Apeldoorn, Netherlands), before walking on paper. At least four stride length values were obtained for each animal, excluding beginning/end and stopping points. Differences between footprint and effects of genotype were tested using a one-way ANOVA $(P<0.05)$.

All animals' weights were recorded at the end of testing. Effects of genotype and sex on weight were analyzed using two-way ANOVA; if a significant effect was detected, the Sidak multiple comparison test was used to identify significant group differences
$(P<0.05)$. All values reported are means $\pm \mathrm{SD}$, unless otherwise stated.

\section{Antibodies}

Mouse monoclonal antibodies against $\mathrm{BK} \alpha$ (L6/60, IgG2a) were obtained from Antibodies Inc. ${ }^{1} \mathrm{HA}$ tag was detected in immunofluorescence using a mouse monoclonal antibody (HA.11, IgG1 isotype, Covance). For immunoprecipitation (IP), a rabbit HA antibody was used (Clone C29F4, Cell Signaling No. 3724). Calbindin antibody was acquired from EMD Millipore for immunofluorescence.

\section{Western Blotting and Immunoprecipitation Tissue Processing}

Mice of the indicated genotypes were euthanized by $\mathrm{CO}_{2}$ inhalation and cervical dislocation. Tissues were rapidly harvested for lysate preparation or flash frozen in liquid nitrogen for later use. For whole lysates, tissues were lysed in modified RIPA buffer (50 mM Tris- $\mathrm{HCl}, 150 \mathrm{mM} \mathrm{NaCl}, 1 \%$ Triton-X, $0.1 \%$ SDS, $0.5 \%$ sodium deoxycholate, $1 \mathrm{mM}$ EDTA, $\mathrm{pH} 7.4$ ) except for IP samples, which were prepared in IP lysis buffer (50 mM HEPES, $137 \mathrm{mM} \mathrm{NaCl}, 1 \%$ Triton-X, 1\% sodium deoxycholate, 5 mM EDTA, pH 7.4, $1 \mathrm{~mL} / 100 \mathrm{mg}$ tissue). For crude membrane lysates, brain hemispheres were lysed in a hypertonic lysis buffer (320 mM sucrose, $5 \mathrm{mM}$ HEPES, pH 7.4). Protease inhibitor cocktail (1:100, Sigma-Aldrich) and 1:1000 freshly prepared saturated phenylmethylsulfonyl fluoride (PMSF) were added to all lysis buffers prior to homogenization. Samples were homogenized using a Dounce homogenizer on ice and centrifuged at $900 \times g$ to pellet debris and nuclei. For crude membrane preps, supernatant was centrifuged at $100,000 \times g$ to pellet membranes; pellet was resuspended in lysis buffer and diluted in SDS sample buffer. Protein was quantified using Bradford and bicinchoninic acid (BCA) assays.

\section{Western Blotting}

Thirty to fifty micrograms protein from whole lysates and $10 \mu \mathrm{g}$ from membrane preps were loaded per well on $7 \%$ or $4-15 \%$ gradient (Bio-Rad) polyacrylamide gels after heating at $37^{\circ} \mathrm{C}$ for $20 \mathrm{~min}$. Prepared whole lysates of $\mathrm{BK} \alpha \mathrm{KO}$ brains were generously provided by Dr. Andrea Meredith. Proteins were blotted onto $0.2 \mu \mathrm{m}$ PVDF membranes using Tris-glycine buffer containing 10\% ethanol. Chemiluminescent detection was performed with Immobilon ECL substrate (EMD Millipore) and imaged using a ChemiDoc Touch imaging system (Bio-Rad). Molecular weight analysis and densitometry were performed using ImageLab software (Bio-Rad).

\section{Immunoprecipitation}

Immunoprecipitation antibodies (rabbit anti-HA monoclonal, mouse anti-BK $\alpha$, clone L6/60) were added to $500 \mu \mathrm{L}$ pre-cleared lysate containing $1 \mathrm{mg}$ protein at a $10 \mu \mathrm{g} / \mathrm{mL}$ concentration and incubated at $4^{\circ} \mathrm{C}$ on a rotator for $2 \mathrm{~h}$. Pre-washed protein G-coated magnetic beads (Thermo Fisher) were added to the

${ }^{1}$ http://www.antibodiesinc.com 
lysates and incubated overnight. Samples were washed $3 \times$ in IP lysis buffer and once in ultrapure $\mathrm{H}_{2} \mathrm{O}$. Protein was eluted by incubation in SDS sample buffer containing 2\% 2mercaptoethanol, $50 \mathrm{mM}$ dithiothreitol at $37^{\circ} \mathrm{C}$. Samples were analyzed by Western blot as described.

\section{Image Acquisition and Analysis Cryosectioning}

Mice were euthanized by isoflurane overdose and fixed by transcardial perfusion of $0.1 \mathrm{M}$ PBS followed by $4 \%$ paraformaldehyde. Brains were removed and post-fixed for 12$24 \mathrm{~h}$ at $4^{\circ} \mathrm{C}$. Brains were washed in PBS and cryoprotected by $36-48 \mathrm{~h}$ incubation in $30 \%$ sucrose in PBS, or until brains sank in solution. Frozen sections $(30 \mu \mathrm{m})$ were cut on a dry-ice cooled cryostat (Leica VT1200; Buffalo Grove, IL, United States) and stored in PBS before histochemical labeling.

\section{Immunofluorescence and MG Labeling of FAP}

For immunostaining, free-floating sections were permeabilized with $0.1 \%$ Triton-X in $0.1 \mathrm{M}$ PBS for $20 \mathrm{~min}$ and were then blocked in primary blocking buffer (10\% normal goat serum, $2 \%$ bovine serum albumin, $0.05 \%$ Triton-X) for $30 \mathrm{~min}$. A second blocking step was performed using $0.125 \mathrm{mg} / \mathrm{mL}$ goat $\mathrm{F}(\mathrm{ab})$ against mouse IgG diluted in primary blocking buffer to block endogenous IgG and Fc receptors. Sections were incubated overnight in indicated antibodies (1:500 BK L6/60, 1:500 HA.11, 1:1000 calbindin). Samples were washed $3 \times 10 \mathrm{~min}$ in PBS containing $0.05 \%$ Triton-X and incubated for $1-2 \mathrm{~h}$ in $4 \mu \mathrm{g} / \mathrm{mL}$ secondary antibodies (Alexa568-conjugated goat anti-mouse, Alexa488-conjugated goat anti-rabbit for single stains. Alexa568conjugated anti-mouse IgG2a and Alexa633-conjugated antimouse IgG1 were used for $\mathrm{BK} \alpha$ and HA co-staining). Secondary antibody was washed out $3 \times 10 \mathrm{~min}$. Samples were incubated for 20 min with $100 \mathrm{nM}$ MG-TCarb or MG-BTau where indicated, concurrently with $0.8-1.6 \mu \mathrm{M}$ Hoechst 33342. Three, $5 \mathrm{~min}$ washes were performed to remove excess dyes. Slices were mounted using SlowFade Diamond (Thermo Fisher) and imaged on a Zeiss 880 laser scanning confocal or Nikon spinning disk confocal (Andor Technologies, Figure 6G).

\section{Image Processing}

Lipofuscin-like fluorescence was identified by detection with 670 long-pass under 488 or $514 \mathrm{~nm}$ excitation due to its broad excitation and emission spectra. Lipofuscin fluorescence was masked in all channels prior to analysis using Imaris for $3 \mathrm{D}$ images and Fiji for 2D images. Deconvolution when applied was performed using a 3D-blind algorithm in NIS Elements (Nikon). Low dynamic range channels were smoothed with a $3 \times 3$ median or Gaussian filter of the approximate point-spread function half width $(0.232 \mu \mathrm{m}$, approximately one pixel radius).

Purkinje cell dendritic fluorescence was measured in 2D sections by measuring mean molecular layer signal normalized to granule layer signal ( $n=10$ fields from $1 \mathrm{WT}$, 16 fields from 2 FAP-BK $\alpha$ Het, 18 fields from 2 FAP-BK $\alpha$ Hom mice). PC soma fluorescence was measured in $2 \mathrm{D}$ optical sections using ImageJ by calculated total cell fluorescence (CTCF), where

$$
\mathrm{CTCF}=\text { Int. Density }-(\text { Area } * \text { Background }) \text {. }
$$

Background was measured by taking ROIs in the granule cell layer, which lacks BK $\alpha$. For analysis, 16 somata from 1 WT, 17 somata from 2 FAP-BK $\alpha$ Het, 17 somata from 2 FAP-BK $\alpha$ Hom mice were used.

Analysis of PC puncta brightness and abundance was performed using a semi-automated algorithm using the spots function of Imaris. For $\beta 4$ experiments, images were acquired from lobes 7 and 8 of the cerebellum of FAP-BK $\alpha$ Het mice. Because Imaris regions of interest are cubic but PC somata are not, identified spots outside the cell of interest were excluded from analysis. Image IDs were blinded for analysis.

\section{RESULTS}

Fluorogen-activating peptides have been extensively used to study protein trafficking in cultured cells (Shruti et al., 2012; Pratt et al., 2015; Yan et al., 2015), but in vivo use is still in its infancy (Wang et al., 2015, 2017; Zhang M. et al., 2015; He et al., 2016). FAP yields a bright and highly photostable, far-red fluorophore, with a molecular brightness that surpasses other genetically encoded red fluorescent proteins (Saurabh et al., 2016). An N-terminally tagged FAP-BK $\alpha$ construct was created to avoid interfering with C-terminal trafficking motifs and to enable surface-exclusive labeling (Figure 1A); this design was previously described for $\mathrm{BK} \alpha$ overexpression experiments in cultured cells (Pratt et al., 2015). With existing MG variants, including cell-excluded MG-BTau (Yan et al., 2015), we observed non-specific targeting of dead and dying cells. To reduce this effect, and for optimal labeling in fixed tissues, we designed the fluorogen MG-TCarb (Figure 1B). Several dyes were designed with negatively charged moieties to inhibit DNA intercalation; the tripod configuration of MGTCarb showed the lowest background and nuclear staining with the highest signal to noise of dyes tested. Electrophysiological measurements of FAP-BK $\alpha$ cDNA in Human embryonic kidney 293 (HEK293) cells showed similar voltage and calcium responses to the untagged version (Figure 1C), indicating that the FAP tag does not interfere with the biophysical properties of $\mathrm{BK} \alpha$.

Using CRISPR, we aimed to express tagged channels that would maintain native expression levels, across multiple splice isoforms. This approach is key due to the extensive and tissue-specific alternative splicing in $\mathrm{BK} \alpha$ (Shipston et al., 1999; Ma et al., 2007; Poulsen et al., 2009; Kyle and Braun, 2014) and controlled stoichiometry with accessory subunits. To that end, a DNA-targeting plasmid and the Cas9 RNA guided nuclease and two sgRNAs were used to insert a FAP cassette into the native $\mathrm{BK} \alpha$ locus, Kcnmal (Figure 2A). PCR spanning the targeted locus using primers flanking the first exon of Kcnmal showed the expected insertion size (Figure 2B); loss of the WT allele in FAP-BK $\alpha$ Hom demonstrated that FAP-BK $\alpha$ and native $\mathrm{BK} \alpha$ are alleles in the same genomic location. Southern blotting with $\mathrm{BK} \alpha$ probes not present on the targeting construct showed hybridization to the expected EcoRV digestion fragments (Figures 2C,D). 


\section{A FAP-BKa}

$\mathrm{N}$

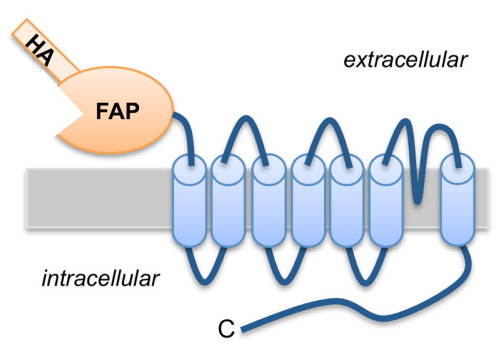

C

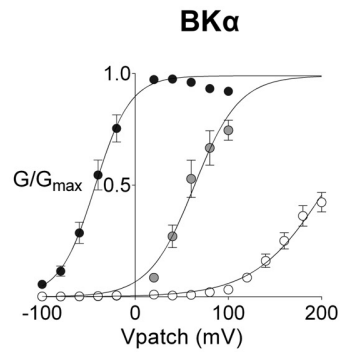

\begin{tabular}{lcc}
\hline$\left[\mathrm{Ca}^{2+}\right]$ & $\mathbf{V}_{\mathbf{5 0}}$ & Slope \\
\hline $100 \mathrm{nM}$ & 206.2 & 38.85 \\
$1 \mu \mathrm{M}$ & 65.24 & 27.51 \\
$10 \mu \mathrm{M}$ & -42.95 & 18.82 \\
\hline
\end{tabular}

B MG-TCarb

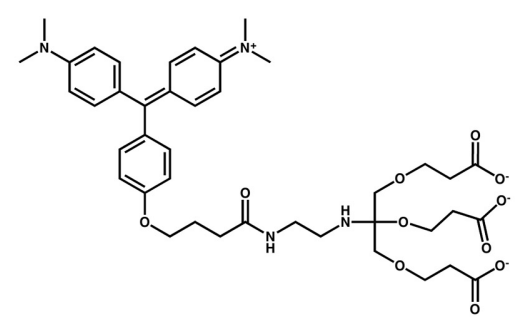

FIGURE 1 | Design of FAP-BK $\alpha$ and MG-TCarb. (A) Peptide layout and membrane topology of FAP-BK $\alpha$ construct. (B) Structure of MG-TCarb dye. Activation by FAP binding produces fluorescence with $633 \mathrm{~nm}$ excitation and $668 \mathrm{~nm}$ emission. (C) Voltage response of FAP-BK $\alpha$ in varying concentrations of Ca ${ }^{2+}$ compared to the same isoform lacking N-terminal HAFFAP tag. Quantification of $V_{50}$ and Hill slope are shown below for each construct.

However, hybridization to BglII-digested DNA revealed a largerthan expected fragment (Supplementary Figure S1). The reason for this was undetermined, as sequencing attempts through this locus with high complexity were unsuccessful.

\section{FAP-BK $\alpha$ Mice Do Not Exhibit Deficits in Motor Coordination}

To verify that FAP does not render $\mathrm{BK} \alpha$ non-functional in vivo and thus impose a dominant-negative phenotype, we asked if FAP-BK $\alpha$ expressing mice would phenocopy $\mathrm{BK} \alpha$ null mice. $\mathrm{BK} \alpha$ knockout mice exhibit profound ataxia and changes in gait (Sausbier et al., 2004; Chen X. et al., 2010), a phenotype also produced by cerebellar microinjection of paxilline, a potent BK channel antagonist (Cheron et al., 2009). To determine if FAP-BK $\alpha$ mice exhibited any of these deficits, WT and transgenic performance was compared using the accelerating rotarod. No differences were observed based on genotype or sex (Figures 3A,B, detailed statistics in Table 1). When gait was analyzed by footprint analysis of stride length, we found no significant differences across genotypes, with the majority of variation coming from individual mice (Figure 3C and Table 2). It is possible that further testing could reveal an effect of FAP$\mathrm{BK} \alpha$ on stride length; however, this effect would seem to be subtle. Because BK $\alpha$ knockout mice show reduced body weight (Sausbier et al., 2004), and because weights could affect stride length, mouse weights were recorded (Figure 3D). As expected, male mice weighed more than their female counterparts; however, no significant effect based on genotype was observed (Table 2). The range of mouse weights appeared to have little bearing on the stride length (Supplementary Figure S2), and short stride length did not appear to associate with poor measures of coordination.

Lastly, we assessed BK channel function in PCs by measuring their spontaneous firing rates in acute slices. Previous work has demonstrated a dependence of spike rate on functional BK channels, in which genetic ablation reduced spike rate (Sausbier et al., 2004; Cheron et al., 2009). We found no difference in spike rate across littermates of the three genotypes [Figures 3E,F, mean firing rate $6.25 \mathrm{~Hz}$; one-way ANOVA genotype, $F_{(2,41)}=0.008$, $P=0.99]$. Treatment with BK channel blockers has also been shown to affect spike rate (Edgerton and Reinhart, 2003); however, addition of $10 \mu \mathrm{M}$ paxilline for $10 \mathrm{~min}$ did not induce any consistent changes in spike rate (data not shown). Unlike previous studies, our experiments were performed at room temperature; it is unknown if increasing temperature would lead to a discernible phenotype or effect of paxilline. We concluded that the FAP-BK $\alpha$ transgene does not influence gross motor coordination, nor does it have overt effects on PC spontaneous firing. Overall, we did not observe any phenotype consistent with non-functioning BK channels. 

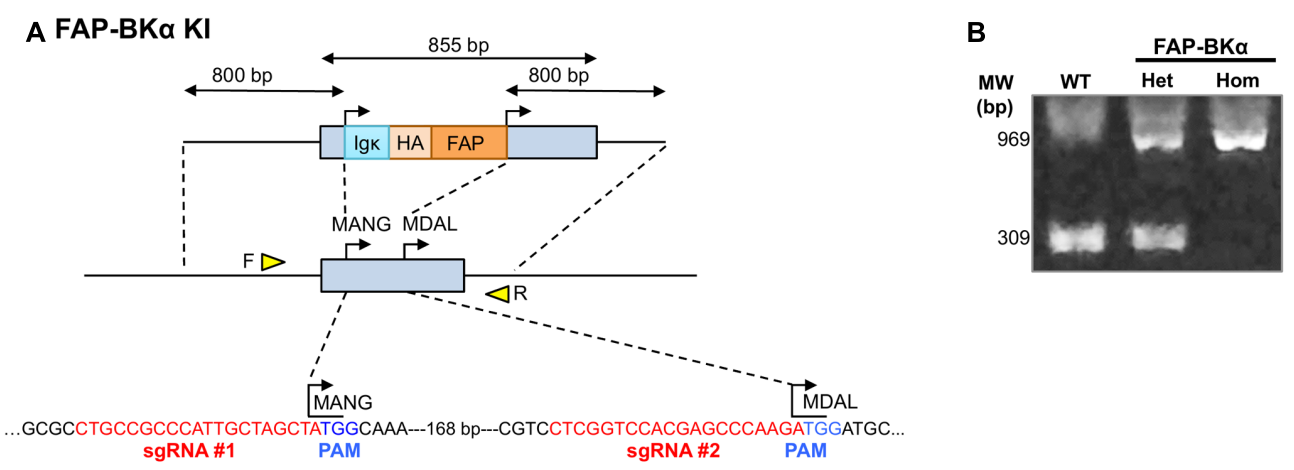

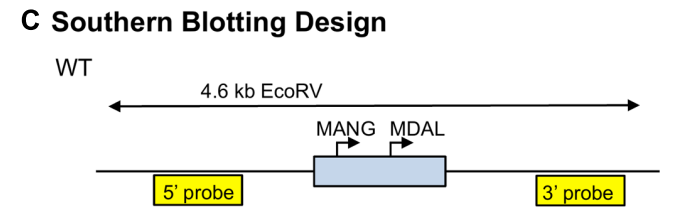

FAP-BKa

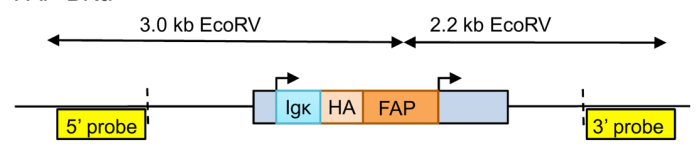

D

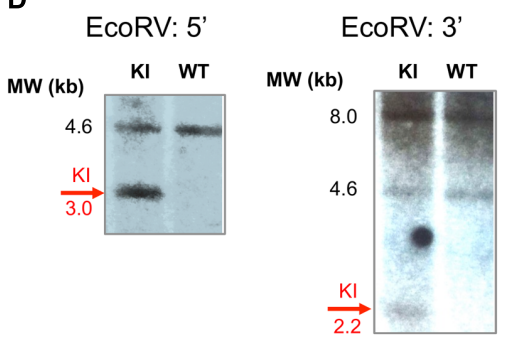

FIGURE 2 | CRISPR-mediated gene targeting. (A) Schematic for CRISPR/Cas9 targeting of Kcnma1 exon 1, showing knock-in (KI) insertion construct. The native Kcnma1 allele is shown below; targeting removed the first start codon (MANG-) and inserted FAP upstream of the downstream start codon (MDAL-). sgRNA sequences for CRISPR targeting are shown in red with protospacer adjacent motifs (PAMs) shown in blue. Primer locations for allele-specific PCR are depicted as yellow triangles. (B) Allele-specific PCR of WT, FAP-BKa het and homozygous mice yields expected band sizes at 309 and 969 bp, respectively, for WT and KI alleles. (C) Schematic for Southern blot analysis of $\mathrm{KI}$ using EcoRV digestion with $3^{\prime}$ and $5^{\prime}$ external hybridization probes. Vertical dashed lines indicate insertion boundaries. (D) Southern blots digestion showed the expected sizes for WT and knock-in (KI) alleles with EcoRV digestion. KI-specific signal is indicated.

\section{FAP-Tagged BK $\alpha$ Subunits Comprise a Subpopulation that Coassembles with Untagged BK $\alpha$}

Protein lysates prepared from whole adult mouse tissues of all three genotypes were analyzed by Western blotting; crude membrane fractions were prepared from $\mathrm{BK} \alpha$ expressing whole brain, kidney, and bladder of WT and knock-in animals and probed for $\mathrm{BK} \alpha$ and $\mathrm{HA}$ immunoreactivity (Figure 4A). In WT brain, $\mathrm{BK} \alpha$ immunoreactivity was observed at the expected molecular weight of $125 \mathrm{kDa}$, with a non-specific band at about $105 \mathrm{kDa}$. In $\mathrm{FAP}-\mathrm{BK} \alpha$ expressing mice, an additional band was observed at approximately $155 \mathrm{kDa}$, a molecular weight shift that corresponded to the HA-FAP insertion. FAP$\mathrm{BK} \alpha$ Hom showed a heavier upper band with a narrowed lower band. Only the upper bands were reactive for HA, suggesting that indeed these are tagged with FAP. No $\mathrm{BK} \alpha$ was detected in kidney membranes, this is likely due to $\mathrm{BK} \alpha$ expression being primarily localized to the collecting ducts and expressed at fairly low levels unless the animal is fed a high potassium diet (Wen et al., 2013). In bladder, the upper bands appeared as in brain, but in FAP-BK $\alpha$ Hom mice, the lower, untagged band disappeared entirely. No HA was detected in the bladder lysates, likely due to signal being below the detection limit. Quantification of total $\mathrm{BK} \alpha$ by summating the 125 and $155 \mathrm{kDa}$ band densities and normalizing to $\mathrm{NaK}$ ATPase in membrane fractions revealed no change in FAP$\mathrm{BK} \alpha \mathrm{Het}$, but significantly reduced total expression in Hom $[n=2$ mice per genotype. Percentage compared to WT $( \pm S D)$ : Het $=90.4( \pm 3.25)$, Hom $=62.8( \pm 6.22)]$.

Western blotting of $\mathrm{BK} \alpha \mathrm{KO}$ whole brain lysates concurrently with a WT, FAP-BK $\alpha$ Het, and Hom trio confirmed antibody specificity (Supplementary Figure S3A). We concluded that this lower band at $125 \mathrm{kDa}$ indeed results from $\mathrm{BK} \alpha$. Two explanations for the presence of these bands are first, that an alternative translation initiation site can result in skipping of the FAP translation in certain peptides, a phenomenon observed in two other potassium channels (Fernandez et al., 2003; Simkin et al., 2008). A second explanation is that a proteolytic cleavage event could remove the tag from the nascent peptide; in human $\mathrm{BK} \alpha$, cleavage has been reported in the S0-S1 intracellular linker (Korovkina et al., 2006). The blots of crude membrane fractions showed no specific HA reactivity at low molecular weights, nor did whole soluble lysates reveal any HA-reactive peptides greater than $15 \mathrm{kDa}$ (Supplementary Figures S3B,C).

Despite the fact that not all $\mathrm{BK} \alpha$ subunits in the brain contain FAP, it is possible that channels could still be tagged by FAP by heterotetramerization of tagged and untagged $\alpha$ 

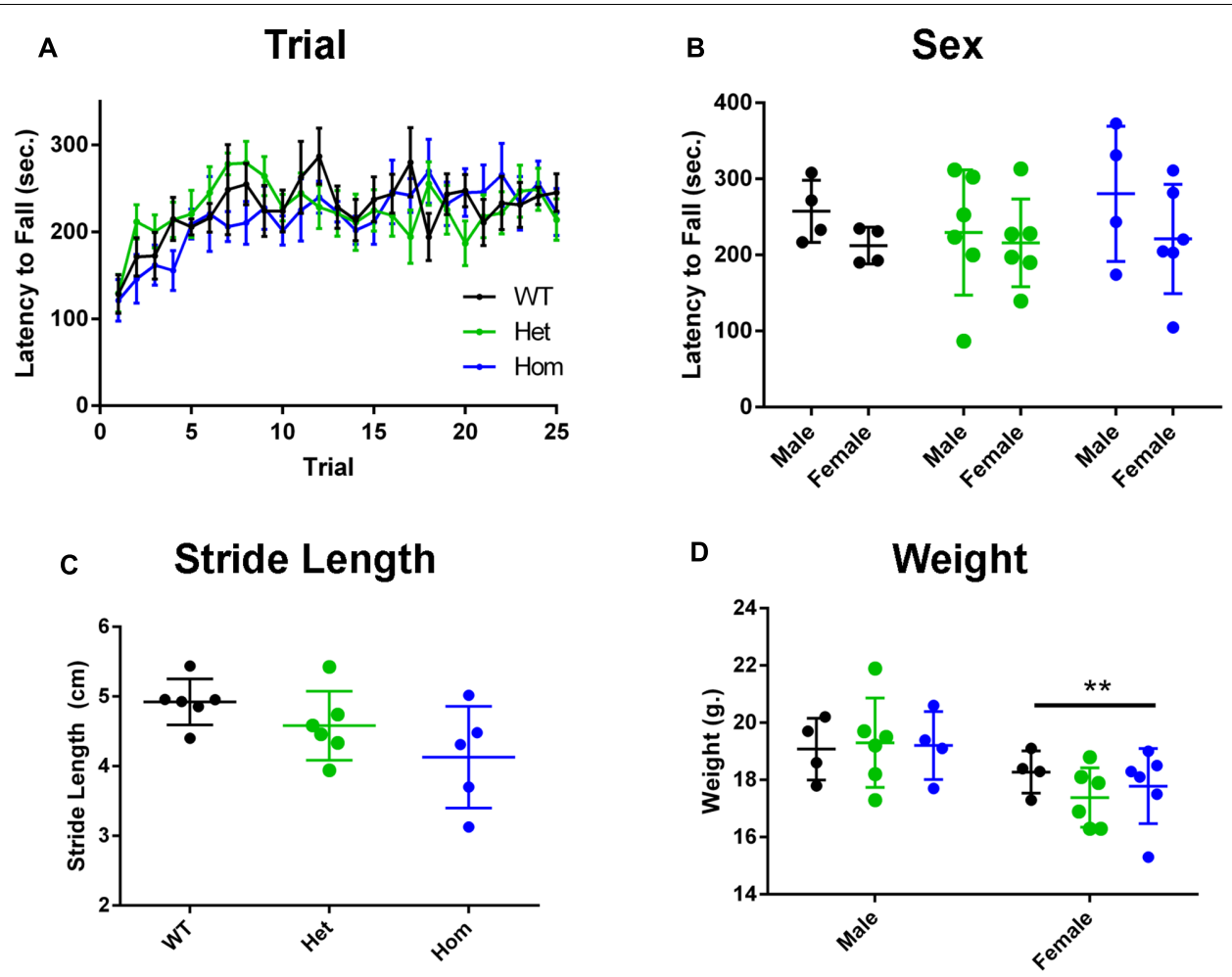

E Spontaneous Firing

F Spontaneous Firing Rate
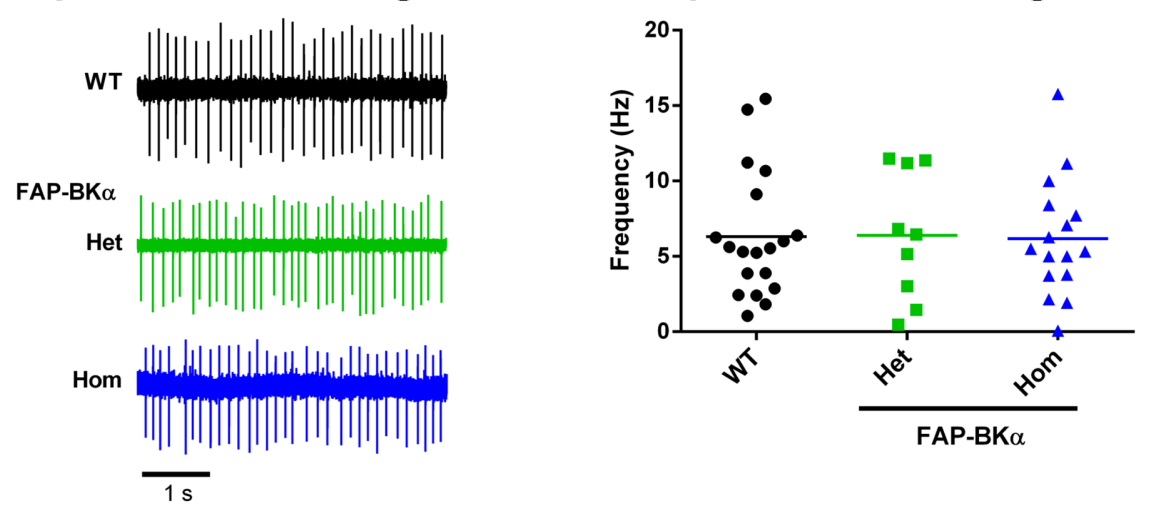

FIGURE 3 | Measurements of FAP-BKa motor effects and PC physiology. (A) Performance on the accelerating rotarod (6-60 × $g$ over $300 \mathrm{~s}, 200 \mathrm{~s}$ sustained) segregated by genotype and trial number. (B) Performance on accelerating rotarod based on sex. (C) Measurements of stride length of WT, FAP-BKa Het and Hom littermates. (D) Measurements of mouse weight segregated by sex and genotype. ${ }^{* *} P \leq 0.01$ based on sex ( $n=$ WT F: 4, M: 2; Het F: 5 F, M: 1; Hom F: 4, M: 1) (E) Example traces from spontaneously firing PCs in acute slices from WT, FAP-BK $\alpha$ Het, and FAP-BK $\alpha$ Hom mice. (F) Quantification of spontaneous spike rate in WT, FAP-BK $\alpha$ Het, and FAP-BK $\alpha$ Hom mice ( $n=$ WT: 4 mice, 19 PCs; Het: 4 mice, 9 PCs; Hom: 3 mice, 16 PCs).

subunits. Alternatively, FAP-BK $\alpha$ could preferentially segregate into its own population of channels. In order to examine this, reciprocal IP experiments were performed using antibodies against $\mathrm{BK} \alpha$ and $\mathrm{HA} ; \mathrm{BK} \alpha$ antibodies should purify both tagged and untagged channels, discernible by Western blotting. If FAPbearing channels homotetramerize into their own population, then IP by HA should only yield $\mathrm{BK} \alpha$ of the high molecular weight. On the other hand, if heterotetramers form, then IP with HA should yield both tagged, $\mathrm{HA}$ reactive $\mathrm{BK} \alpha$, and untagged,
HA-negative $\mathrm{BK} \alpha$. The ratio of tagged:untagged $\mathrm{BK} \alpha$ can be measured to infer a mean FAP stoichiometry (Figure 4B).

BK IP, as expected, yielded both tagged and untagged channels, similarly to input lysates (Figure 4C). Performing the IP protocol on WT lysates using a mouse HA antibody as an IgG control failed to yield any bands. BK $\alpha$ and HA signal were successfully depleted from flowthrough, demonstrating an efficient capture of $\mathrm{BK} \alpha$ and that HA specificity is $\mathrm{BK} \alpha$-dependent. IP using an HA rabbit monoclonal antibody yielded both tagged and 
TABLE 1 | Summary statistics for Rotarod tests.

\begin{tabular}{|c|c|c|c|c|c|}
\hline & sS & MS & $d f$ & $\boldsymbol{F}$ & $P$ \\
\hline \multicolumn{6}{|c|}{ Rotarod performance (trial $\times$ genotype) } \\
\hline Interaction & 267,071 & 5564 & 48 & 0.9917 & 0.4914 \\
\hline Trial & 563,296 & 23,471 & 24 & 4.183 & $<10^{-4}$ \\
\hline Genotype & 13,443 & 6722 & 2 & 0.1799 & 0.8364 \\
\hline Subjects (matching) & $1.01 * 10^{6}$ & 37,372 & 27 & 6.661 & $<10^{-4}$ \\
\hline \multicolumn{6}{|c|}{ Final day Rotarod performance (sex $\times$ genotype) } \\
\hline Interaction & 2969 & 1484 & 2 & 0.3332 & 0.7199 \\
\hline Sex & 11,145 & 11,145 & 1 & 2.502 & 0.1268 \\
\hline Genotype & 4165 & 2083 & 2 & 0.4675 & 0.6322 \\
\hline
\end{tabular}

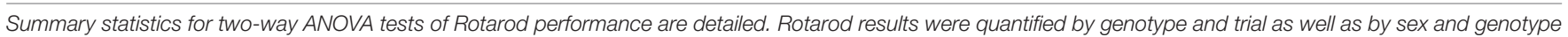
on the final day of testing. SS, sum of squares; MS, mean of squares; df, degrees of freedom; $F$ and $P$ statistics are shown.

TABLE 2 | Summary ANOVA statistics for stride length and weight measurements.

\begin{tabular}{|c|c|c|c|c|c|}
\hline & SS & MS & $d f$ & $\boldsymbol{F}$ & $P$ \\
\hline \multicolumn{6}{|c|}{ Stride length (one way) } \\
\hline Genotype & 1.723 & 0.8614 & 2 & 3.090 & 0.0773 \\
\hline Individual & 3.903 & 0.2788 & 14 & & \\
\hline \multicolumn{6}{|c|}{ Weight (sex $\times$ genotype) } \\
\hline Interaction & 1.501 & 0.7505 & 2 & 0.5063 & 0.6090 \\
\hline Sex & 13.67 & 13.67 & 1 & 9.221 & 0.0057 \\
\hline Genotype & 0.5351 & 0.2676 & 2 & 0.1805 & 0.8360 \\
\hline
\end{tabular}

ANOVA statistics for stride length and weight are shown. SS, sum of squares; MS, mean of squares; df, degrees of freedom; F and P statistics are shown.

untagged subunits (Figure 4D) in which only the upper, $155 \mathrm{kDa}$ bands were HA reactive. IP of WT lysates produced no bands. However, faint bands of approximately $155 \mathrm{kDa}$ remained in the flowthrough that did not show HA reactivity in WB. The identity of these bands is unclear.

We measured the ratio of tagged:untagged channels to characterize the relative abundance of the FAP-tagged variant in whole lysates and HA IPs. In raw lysates, FAP-BK $\alpha$ Het mice had a mean ratio of $0.40( \pm 0.06 \mathrm{SEM}, n=6)$ and FAP-BKa Hom showed a mean ratio of $0.96( \pm 0.19 \mathrm{SEM}, n=6)$ (Figure $4 \mathrm{E})$. This shows roughly a dose-dependent effect of genotype on FAPtagged BK $\alpha$ abundance. With HA IP, FAP-BK $\alpha$ Het shows a ratio of $0.26( \pm 0.05, n=3)$ and Hom showed $1.02( \pm 0.19, n=3)$ (Figure 4F). We concluded that FAP-BKa Het mice generally contain 1 FAP per assembled channel, but not all channels are labeled, resulting in a decrease in ratio following IP as well as persistence of $\mathrm{BK} \alpha$ in flowthrough. FAP-BKa Hom mice have 2 FAPs per channel, again showing the dose-dependence of the genotype on FAP tagging, and this remains remarkably consistent with the whole lysate. However, as in Het mice, Hom also does not tag every channel in the brain.

\section{FAP and BK $\alpha$ Localize to the Same Brain Regions, Strong Expression in Cerebellum}

For studying $\mathrm{BK}$ in the brain, it is necessary to know if FAP-BK $\alpha$ is expressed in the correct cells and subcellular domains to recapitulate native $\mathrm{BK} \alpha$. BK channels are critical for cerebellar function, and are abundantly expressed. Using mouse monoclonal antibodies against $\mathrm{BK} \alpha$ and $\mathrm{HA}$, immunofluorescence staining was performed in sagittal cryosections from WT (Figures 5A,B) and FAP-BKa Hom mice (Figures 5C,D). BK $\alpha$ staining showed a broad expression pattern, with especially stark expression in the cerebellum, hippocampus, globus pallidus, substantia innominata, substantia nigra, and other regions, although $\mathrm{BK} \alpha$ intensity appears to be reduced in some areas. HA staining showed no signal above background in WT, but showed signal mirroring that of BKa in the FAP-BK $\alpha$ Hom. Interestingly, BKa staining intensity was reduced in several areas including substantia nigra and globus pallidus-substantia innominata. FAP-BKa Het brains did not yield acceptable signal-to-noise with HA staining in most brain regions (not shown). The HA staining showed signal in the granule cell layer of dentate gyrus and stratum pyramidale in CA3-CA1. Given that our BKa staining shows an absence in stratum pyramidale, as do previously published immunohistochemistry experiments in rat hippocampus using the same antibody (Misonou et al., 2006), and that a weak signal can also be seen in the WT brain, we interpret this as non-specific signal.

Confocal imaging of cerebellar PCs confirmed strong immunolocalization to PC somata, where a strong putative PM signal is evident, with visible local maxima. As previously observed (Kaufmann et al., 2009) there is moderate intensity in the molecular layer, which contains PC dendrites (Figure 5E). One unexpected result came as a loss in dendritic immunoreactivity in FAP-BKa knock-in animals (Figure 5F, relative dendritic intensity compared to WT: Het $=80 \%$, 

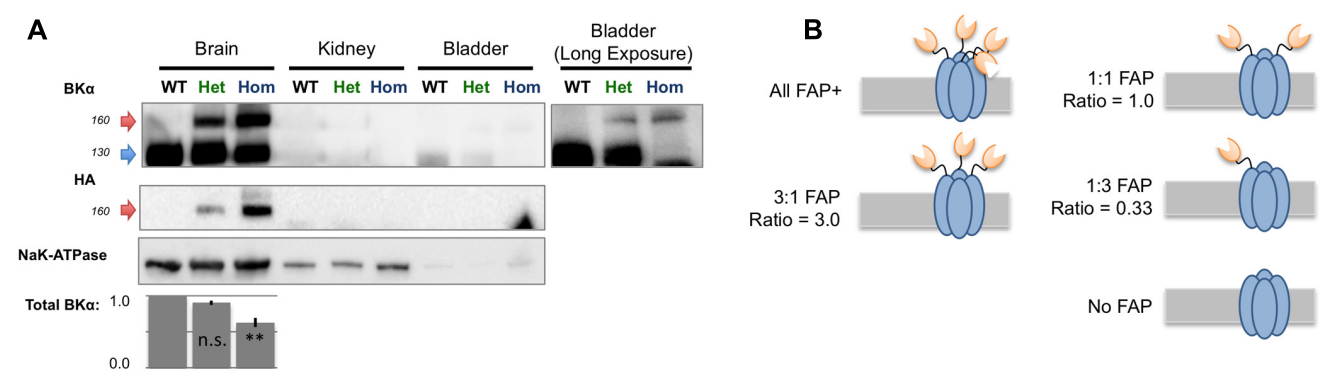

C
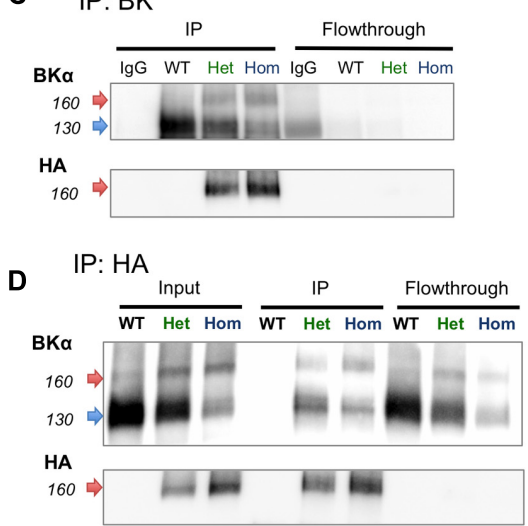

$\mathbf{F}$

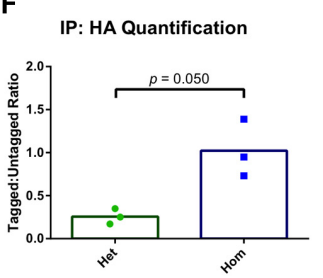

FIGURE 4 | FAP-tagged BKa subunits coassemble with untagged subunits. (A) Crude membrane fractions from brain, kidney, and bladder were probed for BKa and HA tag. Untagged BKa migrated at $125 \mathrm{kDa}$ and FAP-BKa migrated at $155 \mathrm{kDa}$. Both bands were present in brain, with HA reactivity in the $155 \mathrm{kDa}$ band. To visualize weak signal in bladder smooth muscle, a long exposure is shown; however, HA reactivity was undetectable in these preparations. Quantification of total BKa normalized to NaK-ATPase is shown below. $n=2$ biological replicates, error bars are SD. ${ }^{* *} P \leq 0.01$ compared to WT, one-way ANOVA with Tukey's multiple comparison test. (B) Schematic for five possible configurations of BKa:FAP-BKa tetramerization ranging from homomeric FAP-BKa to channels lacking FAP; expected densitometry ratios are given for each condition. (C) Immunoprecipitation using antibodies directed against BKa C-terminus yielded FAP-tagged and untagged channels. FAP-tagged channels showed HA reactivity, which was depleted in flowthrough. (D) Immunoprecipitation using antibodies against HA yielded tagged and untagged channels. Only the high M.W. bands were HA reactive in input and IP. (E,F) Ratios of high and low (155 kDa:125 kDa) BKa-reactive band densitometry in whole lysates (E, $n=4$ animals, 6 protein preparations) and HA immunoprecipitated samples ( $\mathbf{F}, n=2$ animals, 3 protein preparations). Significance tested using unpaired $t$-test with Welch's correction.

Hom $=35 \% . n=10$ fields from 1 WT, 16 fields from 2 Het, 18 fields from 2 Hom mice), while total $\mathrm{BK} \alpha$ signal in PC somata was unchanged (Figure 5G). Together these data show that while immunofluorescence of HA and $\mathrm{BK} \alpha$ are expressed in the same cells, detectable FAP-BK $\alpha$ channels are preferentially localized to the PC soma. Furthermore, FAP-BK $\alpha$ expressing mice appear to have deficits in PC dendritic localization; however, the extent of this disruption is FAP-BK $\alpha$ dose dependent. Despite a reduced brightness of signal, the use of FAP-BK $\alpha$ Het mice for MG-TCarb labeling experiments seemed a worthy compromise to visualize channels while minimizing disruption of $\mathrm{BK} \alpha$ localization, since both Het and Hom animals express untagged channels.

\section{MG Labeling of FAP Recapitulates HA Immunolocalization}

Addition of MG-TCarb produced a fluorescent signal in sagittal posterior brain sections similar to that of $\mathrm{BK} \alpha$ and HA immunolocalization, including bright, specific signal in hippocampus and cerebellum. In the hippocampus (Figures 6A-C), FAP-BK $\alpha$ is localized to expected regions, with an exclusion from CA3 and CA1 pyramidal cell bodies in stratum pyramidale, but robust expression in stratum oriens, stratum lucidum, the site of mossy fiber connections, and stratum lacunosum-moleculare, where Schaffer collaterals provide synaptic input. This is in agreement with previous reports (Hu et al., 2001; Misonou et al., 2006; Cox et al., 2014). Cerebellum (Figures 6D-F) shows strongest FAP signal in PC bodies with moderate fluorescence in the molecular layer, in agreement with $\mathrm{BK} \alpha$ immunostaining and previous reports (Misonou et al., 2006; Kaufmann et al., 2009). Signal is dependent on FAP expression and MG addition (Supplementary Figure S4). A low level of non-specific, dye-related fluorescence does occur with MG-TCarb addition to non-FAP expressing brains; however, the presence of FAP-BK $\alpha$ and dye washout prior to slide mounting suppressed this signal substantially.

We next aimed to confirm that MG labeling of FAP recapitulates HA immunostaining. To that end, we had optimized a labeling paradigm using MG-TCarb, which was designed to minimize dead-cell staining and non-specific activation in fixed tissue. Immunostaining against $\mathrm{HA}$ and subsequently labeling with MG-TCarb revealed bright puncta 

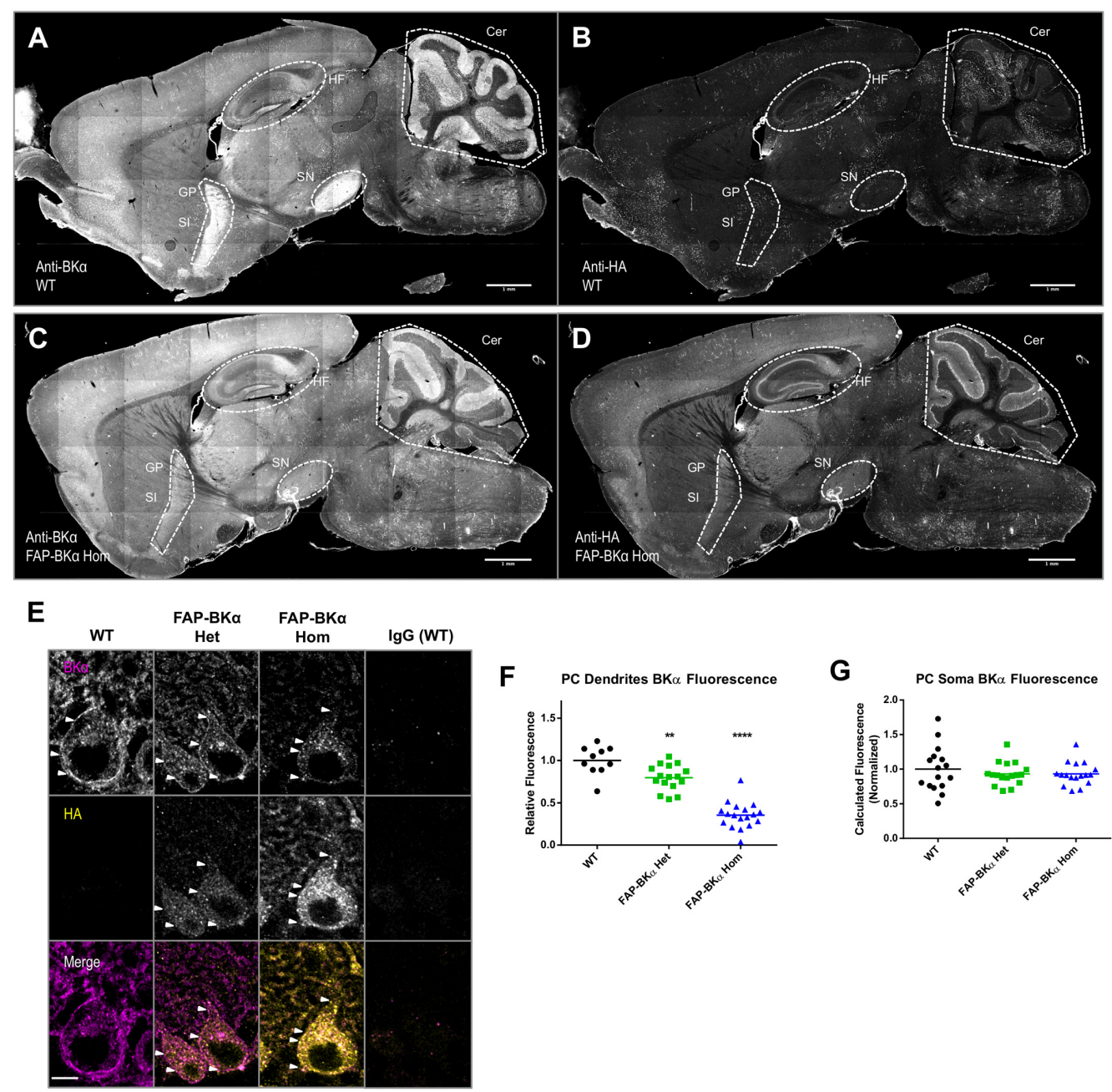

$\mathbf{F}$

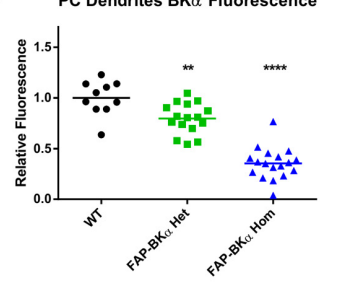

G

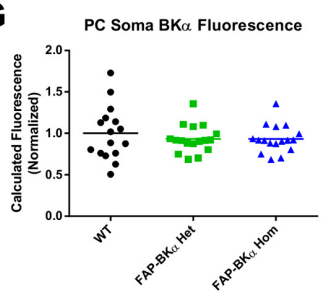

FIGURE 5 | Hemagglutinin (HA) localization corresponds to same brain regions as endogenous BKa; not all BKa in PCs show HA reactivity. Sagittal cryosections of p60 WT (A,B) and FAP-BKa homozygous (C,D) brains were co-stained for BK $\alpha \mathbf{( A , C )}$ and HA (B,D). BKa shows notably strong expression in hippocampal formation (HF), cerebellum (Cer), substantia nigra (SN). Expression is also evident in Substantia innominata (SI) and globus pallidus (GP), which appear as a continuous region. (B) HA staining does not produce specific signal in WT. (D) FAP-BKa Hom mice show localization of HA signal to be similar to BKa. FAP-BK $\alpha$ heterozygous brain is not shown due to insufficient signal-to-noise in whole brain under immunostaining conditions. (E) Confocal sections of PCs show BK $\alpha$ expression in somata and dendrites in the PC and molecular layers, respectively. HA immunoreactivity is more strongly localized to soma than total BKa. White arrowheads point to example local maxima showing BKa and HA signal. (F) Quantification of total BK $\alpha$ fluorescence in PC dendrites (each point corresponds to a field of view from two to three animals of each genotype, normalized to granule cell layer fluorescence). (G) Total calculated cell fluorescence for PC somata, background calculated from granule cell layer. ${ }^{* *} P \leq 10^{-3},{ }^{* * * *} P \leq 10^{-5}$ compared to WT.

in PCs, which were spatially colocalized (Figure 6G, white arrowheads). The brightness of these puncta did not always co-vary linearly, though this likely stems from the different labeling and detection methods. Previous reports using electron microscopy and freeze-fracture showed large clusters containing BK channels at the PM of PC somata (Kaufmann et al., 2009; Indriati et al., 2013), to confirm that these puncta are localized to the $\mathrm{PM}$, we immunostained using the cytoplasmic PC-specific marker calbindin (Figure 6H), where edges represent putative PM. MG-TCarb puncta were localized to the edge of calbindin-positive areas in all three dimensions of imaging, suggesting that these puncta are likely to be PM localized.
Fluorogen-activating peptides labeling has several advantages over antibody-based detection, especially in live cells, including selectable cell permeance or impermeance, high molecular brightness, and labeling with a small molecule label that does not require wash steps. Various MG derivatives find optimal niches in different applications. MG-TCarb is useful for labeling fixed cryosections because of the reduced nonspecific labeling; however, ethanol solvation requirements limit its utility in live cells and sections. In order to prepare this model for future studies, we measured the effects of a cellexcluded dye ideal for live studies, MG-BTau (Yan et al., 2015; Wang et al., 2017), on the electrical properties of neocortical neurons in acute slices. We found that addition of $300 \mathrm{nM}$ 

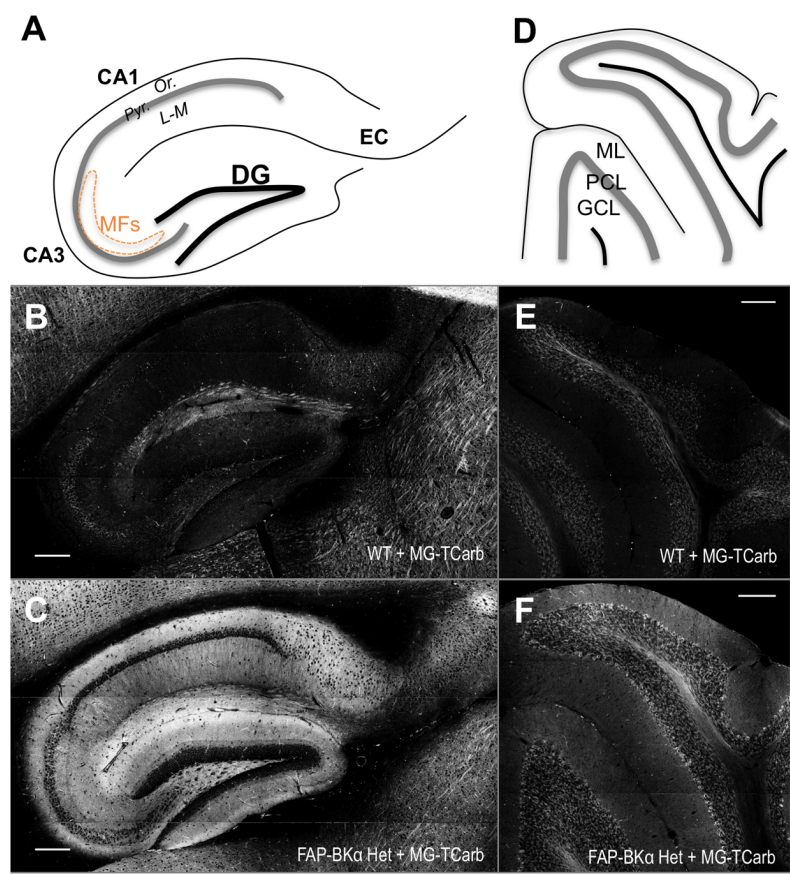

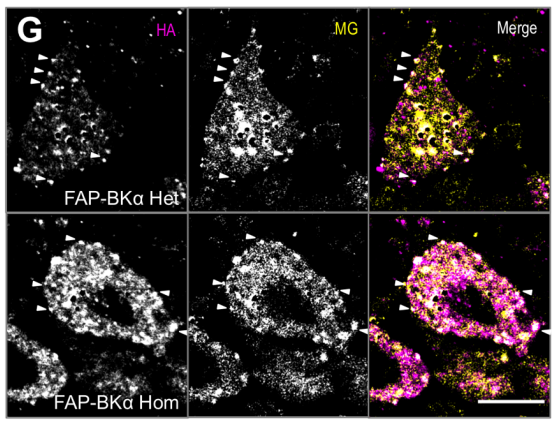

H FAP-BKa Het

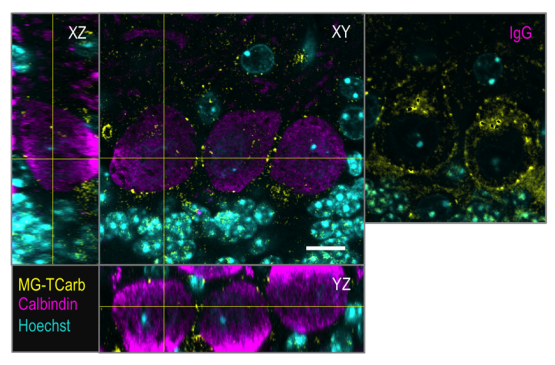

FIGURE 6 | Sagittal sections labeled with MG-TCarb show expected FAP signal in hippocampus and cerebellum. Punctate distribution seen in PCs. (A) Schematic of sagittal hippocampal sections depicting the regions of dentate gyrus (DG), CA3, CA1, and entorhinal cortex (EC). CA layers depicted are stratum pyramidale (Pyr.) stratum oriens (Or.), and stratum lacunosum-moleculare (L-M). Mossy fibers (MFs) in CA3 are depicted by the orange dashed line. (B,C) Images of WT (B) and FAP-BK $\alpha$ Het (C) hippocampi showing FAP-BKa dependent fluorogen activation. Scale bars $200 \mu \mathrm{m}$. (D) Schematic of sagittal cerebellar sections depicting the three main layers: granule cell layer (GCL), Purkinje cell layer (PCL), and molecular layer (ML). (E,F) Images of WT (E) and FAP-BKa Het (F) cerebella showing FAP-BKa-dependent fluorogen activation. Scale bars $200 \mu \mathrm{m}$. (G) Single optical sections of PCs stained with HA antibody (magenta) and labeled with MG-TCarb (yellow) show colocalization to puncta at the cell periphery, with diffuse signal within the cytoplasmic region in FAP-BKa expressing brains. (H) Staining of PC volumes with calbindin (magenta) shows FAP (yellow) puncta are localized to the cell edge in three dimensions. Hoechst 33342 staining (cyan) shows orientation of PC layer with abundant signal in GCL layer below. No calbindin signal is observed in IgG controls. Scale bars $10 \mu \mathrm{m}$.

MG-BTau did not alter resting membrane potential, input resistance, rheobase current, or AP time-course (Supplementary Figure S5).

\section{Loss of $\beta 4$ Impairs Assembly into PM Clusters}

The $\beta 4$ subunit produces BK channels with slower activation and deactivation kinetics and altered sensitivity to calcium (Behrens et al., 2000; Brenner et al., 2000; Lippiat et al., 2003). While $\beta 4$ has an ER-retention motif (Shruti et al., 2012; Cox et al., 2014), the localization of $\beta 4$-containing BK channels to specific PM domains (Dopico et al., 1999; Martin et al., 2004; Wynne et al., 2009; Martire et al., 2010) suggests that cell-type-specific mechanisms are involved to direct these channels to specific PM locations. In PCs, $\mathrm{BK} \alpha / \beta 4$ channels carry the bulk of somatic BK current (Benton et al., 2013). Furthermore, clustering of BK into large intramembrane particles along with $\mathrm{P} / \mathrm{Q}$ type calcium channels has been characterized in PC somata by freeze fracture and EM, with both of these channels being involved in assembly (Kaufmann et al., 2009; Indriati et al., 2013). BK channels also exist in a non-clustered, scattered population. The distinct roles of the clustered and scattered channels are unknown. FAP-BK $\alpha$ effectively reveals these clusters.
In order to minimize experimental variation, we opted to use littermate mice that could be processed in parallel. To this end, we crossed FAP-BK $\alpha$ Hom mice with $\beta 4 \mathrm{KO}$ mice to generate FAP-BK $\alpha$ Het mice with $\beta 4 \mathrm{Het}$ or $\mathrm{KO}$ genotypes. FAP-BK $\alpha$ puncta are readily visible at the cell periphery in the PC layer in single sections (Figures 7A,B). The intensity of diffuse FAP signal does not appear to be an effect of genotype, as cells high in internal fluorescence have also been observed in $\beta 4$ Het tissues, and conversely cells with low internal fluorescence have been observed in $\beta 4 \mathrm{KO}$ tissues (not shown). 3D images were generated from acquired stacks (Figures 7C,D); only cells in which the entire soma is included in the stack were used for quantification. The genotypes were blinded prior to analysis, and unblinded after quantification. Max projection images of whole somata were constructed and cells were analyzed by spots detection using Imaris (Figures 7E,F); the numbers of puncta per PC soma were counted (Figure 7G, mean number of puncta \pm SEM: $\beta 4$ Het: $122.7 \pm 8.55, \beta 4 \mathrm{KO}: 63.73 \pm 6.15$, $P \leq 10^{-4}$, unpaired $t$-test with Welch's correction. $n=17,15$ cells for $\beta 4$ Het and $\beta 4 \mathrm{KO}$, respectively, from 2 male animals per genotype). The puncta brightness was also quantified per spot as the median MG voxel intensity within the spot. The distribution of puncta brightness is significantly reduced in the $\beta 4$ knockout (Figure $7 \mathbf{H}$ ). Together, these data indicate that loss of $\beta 4$ reduces 

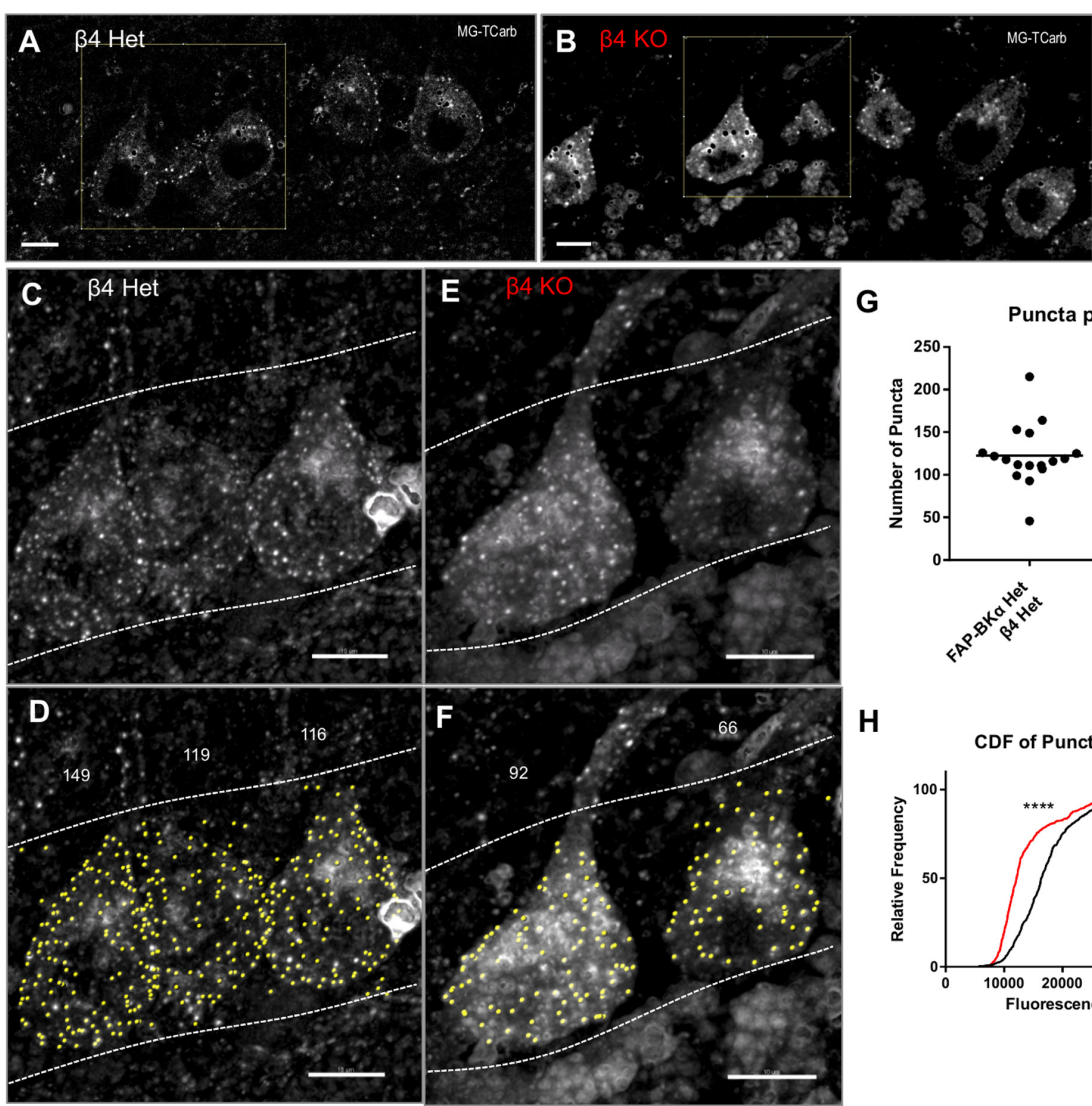

G
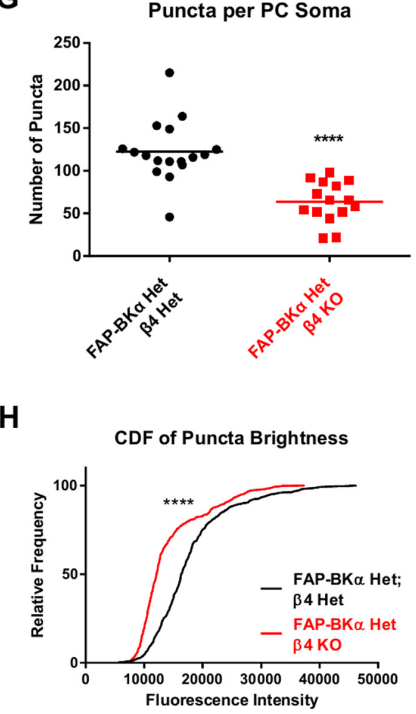

FIGURE 7 | $\beta 4$ knockout reduces the number of PM FAP-BK $\alpha$ puncta in Purkinje neurons in FAP-BKa Het mice. (A) FAP-BKa Het; $\beta 4$ Het brains show PM puncta in single optical sections. Black spots result from lipofuscin masking operations. The yellow square indicates cells in (C,D). (B) $\beta 4 K O$ brains show DPM puncta in single optical sections. The yellow square indicates cells in (E,F). (C) Z-projection of three PC somata showing bright FAP puncta. Dashed lines indicate borders of PCL with GCL below and ML above. (D) Identification of spots (yellow) by Imaris yields punctum counts per cell. Stray spots not clearly assigned to a soma were excluded from analysis. Counts for the given PCs are shown above. Dashed white lines show area of analysis, demarcating the PCL boundaries. (E) Z-projection of $\beta 4 K O$ brains show puncta similar to $\beta 4$ Het. (F) Analysis of $\beta 4 \mathrm{KO}$ PCs performed analogously to (D). (G) Puncta counts per cell for $\beta 4$ Het and $\beta 4 \mathrm{KO}$ brains. ${ }^{* * * *} P \leq 10^{-4}$, unpaired $t$-test with Welch's correction. (H) Cumulative distribution function for all counted puncta by genotype. ${ }^{* * * *} P \leq 10^{-4}$, Mann-Whitney rank sum test.

the number of membrane puncta present in PCs by nearly a factor of two. Additionally, based on fluorescence intensity, the average number of channels incorporated into each punctum is also reduced. This approach only allowed us to examine the effects of total loss of $\beta 4$ on clustering, since our breeding strategy resulted in a lack of $\beta 4$ WT mice. We hypothesize that the assembly of clusters could be further pronounced in $\beta 4 \mathrm{WT}$ animals, but the necessary stoichiometry of $\beta 4$ to exert a trafficking effect is unknown.

\section{DISCUSSION}

BK channels are critical determinants of cell activity, enabling rapid firing through their strong repolarizing current and rapid deactivation. BK is especially important in PCs for enabling complex spikes, which are critical for reflex learning and motor coordination. Mice lacking $\mathrm{BK} \alpha$ channels are viable; however, they suffer from cerebellum-based motor deficits (Sausbier et al., 2004; Chen X. et al., 2010). Knocking out $\beta 4$ is sufficient to produce seizure activity, but mice do not have measurable motor deficits (Brenner et al., 2005). The observed effects of $\beta 4$ loss may be based both on trafficking and kinetic alterations of BK currents; in dentate gyrus, which possess surface BK $\alpha \beta 4$ channels, loss of $\beta 4$ enhances excitability by enhancing coupling to internal calcium stores and through increased BK activation and deactivation speeds (Brenner et al., 2005; Wang et al., 2016). In the $\mathrm{CA} 3$ region of the hippocampus, where the $\beta 4 \mathrm{ER}$ retention motif effectively sequesters BK channels, $\beta 4$ knockout enhances surface $B K$ abundance, facilitating rapid spiking by increasing BK current flux. Biophysical studies using these knockouts, specific inhibitors, and electrophysiology have yielded great knowledge at the general role of BK channels, as well as some of the proteinlevel effects of signaling, $\beta$ subunit incorporation, and alternative splicing. However, these experiments only tell a part of the story.

We generated the FAP-BK $\alpha$ mouse, the first genetically engineered animal in which $\mathrm{BK} \alpha$ is tagged with a detectable substrate, which enables the visualization and study of BK channels under endogenous control of expression and splicing. 
FAP-BK $\alpha$ failed to label all channels in the brain; however, FAP$\mathrm{BK} \alpha$ appears to have similar localization properties to native $\mathrm{BK} \alpha$. In $\mathrm{PC}$ somata, however, $\mathrm{FAP}-\mathrm{BK} \alpha$ strongly visualized channel clusters previously seen only using electron microscopy (Kaufmann et al., 2009; Indriati et al., 2013). Like these previous studies, BK-containing clusters were limited to the soma and proximal dendrite; the reason for their enhanced fluorescence could lie in the different detection methods of using FAPMG labeling versus immunofluorescence. Importantly, FAP-BK $\alpha$ homomers appear to retain voltage and calcium sensitivity in heterologous cells, and FAP-BK $\alpha$ Het and Hom mice do not appear to have gross motor deficits or seizures, symptoms of $\mathrm{BK} \alpha$ loss or gain of function (Sausbier et al., 2004; Shruti et al., 2008; Chen X. et al., 2010). We did not observe any change in PC spontaneous firing; however, the lack of an effect of paxilline on output is concerning. It is possible that our approach at room temperature in acute slices does not reproduce BKdependent effects previously described (Edgerton and Reinhart, 2003; Sausbier et al., 2004; Cheron et al., 2009). The presence of untagged channels, however, could feasibly compensate for or obfuscate any functional deficits in our tests. Future studies will be necessary to confirm normal BK currents in various cell types. While FAP-BK $\alpha$ tagged channels do not label all channels, they effectively tetramerize with untagged channels, resulting in a plurality of tagged channels, which appear to have similar localization to untagged channels and can thus be used as detectable fluorescent reporters without overexpression.

\section{BK $\alpha$ May Have Tissue-Specific N-termini}

BK channels exhibit vast variation in biophysical properties, in part due to extensive alternative splicing of $\mathrm{BK} \alpha$; this makes biologically relevant experiments by cDNA-based overexpression difficult. Multiple splice variants are expressed within a given tissue, with tissue-specific isoforms (Poulsen et al., 2009), which can form heterotetramers (Ma et al., 2007; Chen L. et al., 2010). Given our removal of upstream start sites, it was a surprise that untagged $\mathrm{BK} \alpha$ persisted even in the FAP-BK $\alpha$ homozygotes. We did not identify a detectable cleavage of FAP from $\mathrm{BK} \alpha$; we reasoned that there could either be a rapid degradation of a cleaved FAP tag, or that translation start selection occurs, a phenomenon that has been observed in several potassium channels (Fernandez et al., 2003; Simkin et al., 2008). Interestingly, our data indicated that this effect is tissue specific, as this untagged variant was not observed in bladder smooth muscle. Additionally, the brain-specific putative untagged $125 \mathrm{kDa}$ band in FAP-BK $\alpha$ Hom appeared narrowed compared to WT and FAP-BK $\alpha$ Het mice; however, the resolution was insufficient for reliable quantification of this phenomenon. Since $\mathrm{BK} \alpha$ is not subject to extensive glycosylation (Hagen and Sanders, 2006) and considering the strategy for generation of the transgene, the missing upper component to this band could correspond to variants produced from the deleted MANGtranslation start site.

Based on our Western blots, we concluded that in whole brain, about $25 \%$ of $\mathrm{BK} \alpha$ included the FAP in Het, and $50 \%$ included the FAP in Hom mice, showing a genetic dose-dependence of expression. Interestingly, it appeared that FAP-BK $\alpha$ Hom had a weakened dendritic profile in PCs. Whether the FAP impairs dendritic trafficking or if the extended N-terminus that was removed in the FAP-BK $\alpha$ Hom mice is required for proper localization in PCs is an open question. This effect appeared specific to PCs; FAP signal in hippocampus showed prominent localization to distal processes in stratum oriens, stratum lacunosum-moleculare, and mossy fibers, but low expression in stratum pyramidale, as previously described (Misonou et al., 2006). Despite this change in BK localization in FAP-BKa homozygous mice, our measurements identified no motor defects. It intuits that the effects of altered subcellular $\mathrm{BK}$ localization would be more subtle than outright loss; this is evidenced by a lack of motor phenotype in $\beta 4$ knockout mice (Brenner et al., 2005).

This mouse model, however, is not without limitations. Most notably, the unsuccessful characterization of the $5^{\prime}$-end of the insertion leaves open the possibility that regulatory elements crucial for $\mathrm{BK} \alpha$ expression or splicing are altered; potentially producing abnormal $\mathrm{BK} \alpha$ variants or misexpression in the brain. Immunostaining and Western blotting both showed decreased $\mathrm{BK} \alpha$ signal in the brain, particularly in the homozygous mouse, which could potentially be due to unidentified changes in the vicinity of the targeted locus. An additional consideration is that a detailed transcript analysis was not successful, so while the inclusion of FAP in multiple splice isoforms is expected based on the intact Kcnmal locus $3^{\prime}$ of the insertion, it was not measured directly. If there is non-native regulation at play, the use of FAP-BK $\alpha$ Het mice can obviate these issues, and have FAP act as a passenger on otherwise normal heteromeric channels.

\section{$\beta 4$ Regulation of Trafficking Is Not Limited to ER Retention}

The $\beta 4$ subunit has been described to restrict surface expression of BK channels in heterologous cells and CA3 pyramidal cells by the action of a novel ER retention motif (Shruti et al., 2012; Cox et al., 2014). This effect is dependent on cell type, with dentate gyrus granule cells and PCs natively exhibiting a population of surface $\mathrm{BK} \alpha \beta 4$ channels (Brenner et al., 2005; Benton et al., 2013). It seems likely that specific machinery or receptors are required for forward trafficking of $\beta 4$ containing channels, as $\beta 4$ is localized specifically to axons in several neuron types (Dopico et al., 1999; Misonou et al., 2006; Wynne et al., 2009) and exclusively to somatodendritic compartments in another (Martin et al., 2004). $\beta 4$ is also crucial for localizing BK channels to apical membranes in the collecting duct of the kidney (Wen et al., 2013). It may be that ER retention is the dominant mode in heterologous cells where the requisite forward trafficking machinery for $\mathrm{BK} \alpha \beta 4$ channels is lacking (Shruti et al., 2012). In cells that show ER retention, such as CA3 pyramidal cells, it is feasible that specific inputs could release this pool.

Our work adds to the body of evidence for a cell-type-specific role of $\beta 4$ in localizing surface BK channels. In PCs, $\beta 4$ functions to facilitate channel localization to large somatic channel clusters, a phenomenon previously observed by electron microscopy (Kaufmann et al., 2009; Indriati et al., 2013). These previous studies determined a density of nine clusters per $100 \mu^{2}$; 
envisioned as a $10 \mu \mathrm{m}$ diameter sphere, this would be roughly 113 clusters per soma. Our results identifying 123 puncta per soma seem remarkably consistent with this. It is unknown how these channel clusters are formed, but the knockout of individual cluster components such as $\mathrm{Ca}_{\mathrm{v}} 2.1$, SK2, or BK channels, was shown to reduce cluster density (Indriati et al., 2013). A question to explore is whether $\beta 4$ loss reduces the total number of clusters, or if it simply restricts BK channel incorporation. Unfortunately, our experimental workflow did not quantify $\beta 4$ WT mice; it is possible that with WT levels of $\beta 4$, more clusters would appear and enable us to examine a dosage relationship of $\beta 4$ on BK channel clustering. Future experiments will aim to address this question. It is also possible that $\beta 4$ knockout produces an enhancement of diffuse surface BK signal, but this was unclear in our system and will likely require dissociated cultures. While PCs are not alone in possessing clustered BK channels (Kaufmann et al., 2009, 2010), they do contain the largest clusters. The mechanisms of $\beta 4$-directed localization to clusters and other PM domains in PCs and other neurons remain an enticing line of questions that may be answered using this model. Future studies will aim to address these questions and determine the roles that slow gated, $\beta 4$-containing BK channels, or fast, $\beta 4$-lacking $\mathrm{BK}$ channels may play in these domains to regulated neuronal function.

\section{Uses of the FAP-BK $\alpha$ Model}

The far-red excitation and emission of the FAP-MG complex is useful for imaging in fixed tissue and does not require the long process of immunofluorescence for detection; furthermore, the far red spectrum leaves plenty of bandwidth for shorter wavelength single photon and two-photon probes. Non-specific fluorogen activation in nucleus posed an occasional problem in fixed tissue, an effect seen previously with labeling of dead cell nuclei (Yan et al., 2015). While development of MG-TCarb greatly reduced this issue, it did occasionally appear; we were unable to identify any particular condition with fixation or sectioning that contributed to this, but it was most present in WT brains where dye is not sequestered by its specific binding. In our validation of MG-TCarb labeling specificity compared to the HA tag, we found some regions where the intensities of HA labeling and MG-TCarb labeling do not linearly co-vary, likely due to differences in the detection method. Immunostaining could show variation in brightness based on several factors including accessibility of the epitope to primary antibody, the number of secondary antibodies bound to the primary for signal amplification, and binding specificity. On the other hand, MGTCarb will always bind at most one FAP, resulting in a single fluorophore per tagged subunit, with increased access by virtue of being a small molecule.

Fluorogen-activating peptides exhibits its greatest strength in living cells, where charge-based cell impermeability can enable the visualization of exclusively surface proteins (Pratt et al., 2015; Yan et al., 2015). Our attempts to visualize FAP in acute living slices were hampered by non-specific contributions from dying cells, but this could be applied to organotypic slice cultures, where the cell exclusion is intact and the far-red spectrum enables tissue penetration. As an important factor for these future experiments, we confirmed that the cell-excluded MGBTau dye does not in itself change any of the electrical properties of neocortical neurons. Because aberrant BK trafficking may underlie kindling and seizure sensitization (Shruti et al., 2008), future experiments are aimed at examining dynamic regulation of BK channel trafficking in dissociated cultures taken from this model. Activity-dependent regulation of channel localization has been observed in other potassium channels (Kim J. et al., 2007; Connors et al., 2008). Dissociated neurons and organotypic explants derived from the FAP-BK $\alpha$ Het mouse line would contain tagged channels under near native expression levels, results gained would not be subject to overexpression artifacts, and preservation of native splicing control would allow focus on the most relevant isoforms, even if not every channel is tagged. The FAP system is sufficiently bright and photostable for singlemolecule tracking (Saurabh et al., 2016). Live cell experiments examining channel redistribution are possible in this biologically relevant context with proper $\mathrm{BK} \alpha$ stoichiometry with $\beta$ and $\gamma$ subunits.

\section{ETHICS STATEMENT}

All experiments were approved by the Institutional Animal Care and Use Committee of Carnegie Mellon University.

\section{AUTHOR CONTRIBUTIONS}

$\mathrm{CP}, \mathrm{MB}$, and $\mathrm{AB}$ designed research. $\mathrm{CP}$ and $\mathrm{DAK}$ performed research and analyzed data. GH and CP designed CRISPR. $\mathrm{SD}$ and $\mathrm{MH}$ performed electrophysiology to characterize FAP$\mathrm{BK} \alpha$ properties. JH and $\mathrm{DK}$ designed and synthesized MGTCarb.

\section{FUNDING}

This work was supported by the National Institutes of Health (T32 NS07433: CP; R21MH100612: MB, CP, and AB; R21NS092109: DAK and AB; AA020889: GH) and European Union InterReg VA (Health \& Life Sciences) Program: SD and $\mathrm{MH}$.

\section{ACKNOWLEDGMENTS}

The authors gratefully acknowledge Brigitte Schmidt for synthesis of dyes, Dr. Andrea Meredith for provision of $\mathrm{BK} \alpha$ knockout mouse brain lysates, and Carolyn Ferguson for expert technical assistance.

\section{SUPPLEMENTARY MATERIAL}

The Supplementary Material for this article can be found online at: https://www.frontiersin.org/articles/10.3389/fncel. 2017.00337/full\#supplementary-material 


\section{REFERENCES}

Behrens, R., Nolting, A., Reimann, F., Schwarz, M., Waldschütz, R., and Pongs, O. (2000). hKCNMB3 and hKCNMB4, cloning and characterization of two members of the large-conductance calcium-activated potassium channel beta subunit family. FEBS Lett. 474, 99-106. doi: 10.1016/S0014-5793(00)01584-2

Benton, M. D., Lewis, A. H., Bant, J. S., and Raman, I. M. (2013). Iberiotoxin-sensitive and -insensitive BK currents in Purkinje neuron somata. J. Neurophysiol. 109, 1-38. doi: 10.1152/jn.00127.2012

Brenner, R., Chen, Q. H., Vilaythong, A., Toney, G. M., Noebels, J. L., and Aldrich, R. W. (2005). BK channel beta4 subunit reduces dentate gyrus excitability and protects against temporal lobe seizures. Nat. Neurosci. 8, 1752-1759. doi: $10.1038 / \mathrm{nn} 1573$

Brenner, R., Jegla, T. J., Wickenden, A., and Liu, Y. (2000). Cloning and functional characterization of novel large conductance calcium-activated potassium channel $\beta$ subunits, hKCNMB3 and hKCNMB4. J. Biol. 275, 6453-6461. doi: $10.1074 /$ jbc.275.9.6453

Chen, L., Jeffries, O., Rowe, I. C. M., Liang, Z., Knaus, H. G., Ruth, P., et al. (2010). Membrane trafficking of large conductance calcium-activated potassium channels is regulated by alternative splicing of a transplantable, acidic trafficking motif in the RCK1-RCK2 Linker. J. Biol. Chem. 285, 23265-23275. doi: 10.1074/jbc.M110.139758

Chen, X., Kovalchuk, Y., Adelsberger, H., Henning, H. A., Sausbier, M., Wietzorrek, G., et al. (2010). Disruption of the olivo-cerebellar circuit by Purkinje neuron-specific ablation of BK channels. Proc. Natl. Acad. Sci. U.S.A. 107, 12323-12328. doi: 10.1073/pnas.1001745107

Cheron, G., Sausbier, M., Sausbier, U., Neuhuber, W., Ruth, P., Dan, B., et al. (2009). BK channels control cerebellar purkinje and golgi cell rhythmicity in vivo. PLOS ONE 4:e7991. doi: 10.1371/journal.pone.0007991

Chiu, Y.-H., Alvarez-Baron, C., Kim, E., and Dryer, S. (2010). Dominant-negative regulation of cell surface expression by a pentapeptide motif at the extreme $\mathrm{COOH}$ terminus of an Slo1 calcium-activated potassium channel splice variant. Mol. Pharmacol. 77, 497-507.

Connors, E. C., Ballif, B. A., and Morielli, A. D. (2008). Homeostatic regulation of Kv1.2 potassium channel trafficking by cyclic AMP. J. Biol. Chem. 283, 3445-3453. doi: 10.1074/jbc.M708875200

Contet, C., Goulding, S. P., Kuljis, D. A., and Barth, A. L. (2016). BK channels in the central nervous system. Int. Rev. Neurobiol. 128, 281-342. doi: 10.1016/bs. irn.2016.04.001

Cox, N., Toro, B., Pacheco-Otalora, L. F., Garrido-Sanabria, E. R., and Zarei, M. M. (2014). An endoplasmic reticulum trafficking signal regulates surface expression of $\beta 4$ subunit of a voltage- and $\mathrm{Ca}(2+)$-activated $\mathrm{K}(+)$ channel. Brain Res. 1553, 12-23. doi: 10.1016/j.brainres.2014.01.028

Dopico, A. M., Widmer, H., Wang, G., Lemos, J. R., and Treistman, S. N. (1999). Rat supraoptic magnocellular neurones show distinct large conductance, Ca2+activated $\mathrm{K}+$ channel subtypes in cell bodies versus nerve endings. J. Physiol. 519(Pt 1), 101-114.

Du, W., Bautista, J. F., Yang, H., Diez-Sampedro, A., You, S.-A., Wang, L., et al. (2005). Calcium-sensitive potassium channelopathy in human epilepsy and paroxysmal movement disorder. Nat. Genet. 37, 733-738. doi: 10.1038/ ng1585

Edgerton, J. R., and Reinhart, P. H. (2003). Distinct contributions of small and large conductance $\mathrm{Ca} 2+$-activated $\mathrm{K}+$ channels to rat Purkinje neuron function. J. Physiol. 548, 53-69. doi: 10.1113/jphysiol.2002.027854

Erxleben, C. (2002). Interacting effects of $\mathrm{N}$-terminal variation and strex exon splicing on slo potassium channel regulation by calcium, phosphorylation, and oxidation. J. Biol. Chem. 277, 27045-27052. doi: 10.1074/jbc.M203087200

Fernandez, F. R., Morales, E., Rashid, A. J., Dunn, R. J., and Turner, R. W. (2003). Inactivation of Kv3.3 potassium channels in heterologous expression systems. J. Biol. Chem. 278, 40890-40898. doi: 10.1074/jbc.M304235200

Gabriel, L., Lvov, A., Orthodoxou, D., Rittenhouse, A. R., Kobertz, W. R., and Melikian, H. E. (2012). The acid-sensitive, anesthetic-activated potassium leak

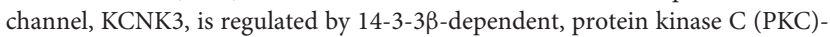
mediated endocytic trafficking. J. Biol. Chem. 287, 32354-32366. doi: 10.1074/ jbc.M112.391458

Gonzalez-Perez, V., Xia, X.-M., and Lingle, C. J. (2014). Functional regulation of BK potassium channels by $\gamma 1$ auxiliary subunits. Proc. Natl. Acad. Sci. U.S.A. 111, 4868-4873. doi: 10.1073/pnas.1322123111
Gonzalez-Perez, V., Xia, X.-M., and Lingle, C. J. (2015). Two classes of regulatory subunits coassemble in the same BK channel and independently regulate gating. Nat. Commun. 6:8341. doi: 10.1038/ncomms9341

Griguoli, M., Sgritta, M., and Cherubini, E. (2016). Presynaptic BK channels control transmitter release: physiological relevance and potential therapeutic implications. J. Physiol. 594, 3489-3500. doi: 10.1113/JP271841

Gu, N., Vervaeke, K., and Storm, J. F. (2007). BK potassium channels facilitate high-frequency firing and cause early spike frequency adaptation in rat CA1 hippocampal pyramidal cells. J. Physiol. 580, 859-882. doi: 10.1113/jphysiol. 2006.126367

Hagen, B. M., and Sanders, K. M. (2006). Deglycosylation of the Betal-subunit of the BK channel changes its biophysical properties. Am. J. Physiol. Cell Physiol. 291, 750-756. doi: 10.1152/ajpcell.00116.2006

He, J., Wang, Y., Missinato, M. A., Onuoha, E., Perkins, L. A., Watkins, S. C., et al. (2016). A genetically targetable near-infrared photosensitizer. Nat. Methods 13, 263-268. doi: 10.1038/nmeth.3735

Hu, H., Shao, L.-R., Chavoshy, S., Gu, N., Trieb, M., Behrens, R., et al. (2001). Presynaptic $\mathrm{Ca} 2+$-activated $\mathrm{K}+$ channels in glutamatergic hippocampal terminals and their role in spike repolarization and regulation of transmitter release. J. Neurosci. 21, 9585-9597.

Indriati, D. W., Kamasawa, N., Matsui, K., Meredith, A. L., Watanabe, M., and Shigemoto, R. (2013). Quantitative localization of Cav2.1 (P/Q-Type) voltage-dependent calcium channels in purkinje cells: somatodendritic gradient and distinct somatic coclustering with calcium-activated potassium channels. J. Neurosci. 33, 3668-3678. doi: 10.1523/JNEUROSCI.2921-12.2013

Kang, J., Huguenard, J. R., and Prince, D. A. (1996). Development of BK channels in neocortical pyramidal neurons. J. Neurophysiol. 76, 188-198.

Kaufmann, W. A., Ferraguti, F., Fukazawa, Y., Kasugai, Y., Shigemoto, R., Laake, P., et al. (2009). Large-conductance calcium-activated potassium channels in purkinje cell plasma membranes are clustered at sites of hypolemmal microdomains. J. Comp. Neurol. 515, 215-230. doi: 10.1002/cne.22066

Kaufmann, W. A., Kasugai, Y., Ferraguti, F., and Storm, J. F. (2010). Two distinct pools of large-conductance calcium-activated potassium channels in the somatic plasma membrane of central principal neurons. Neuroscience 169, 974-986. doi: 10.1016/j.neuroscience.2010.05.070

Kim, E. Y., Zou, S., Ridgway, L. D., and Dryer, S. E. (2007). Beta1-subunits increase surface expression of a large-conductance $\mathrm{Ca} 2+$-activated $\mathrm{K}+$ channel isoform. J. Neurophysiol. 97, 3508-3516. doi: 10.1152/jn.00009.2007

Kim, J., Jung, S.-C., Clemens, A. M., Petralia, R. S., and Hoffman, D. A. (2007). Regulation of dendritic excitability by activity-dependent trafficking of the A-type $\mathrm{K}+$ channel subunit Kv4.2 in hippocampal neurons. Neuron 54, 933-947. doi: 10.1016/j.neuron.2007.05.026

Korovkina, V. P., Brainard, A. M., and England, S. K. (2006). Translocation of an endoproteolytically cleaved maxi-K channel isoform: mechanisms to induce human myometrial cell repolarization. J. Physiol. 573, 329-341. doi: 10.1113/ jphysiol.2006.106922

Kyle, B. D., and Braun, A. P. (2014). The regulation of BK channel activity by preand post-translational modifications. Front. Physiol. 5:316. doi: 10.3389/fphys. 2014.00316

Lippiat, J. D., Standen, N. B., Harrow, I. D., Phillips, S. C., and Davies, N. W. (2003). Properties of $\mathrm{BK}(\mathrm{Ca})$ channels formed by bicistronic expression of hSloalpha and beta1-4 subunits in HEK293 cells. J. Membr. Biol. 192, 141-148. doi: 10.1007/s00232-002-1070-0

Ly, C., Melman, T., Barth, A. L., and Ermentrout, G. B. (2011). Phase-resetting curve determines how BK currents affect neuronal firing. J. Comput. Neurosci. 30, 211-223. doi: 10.1007/s10827-010-0246-3

Ma, D., Nakata, T., Zhang, G., Hoshi, T., Li, M., and Shikano, S. (2007). Differential trafficking of carboxyl isoforms of Ca2+-gated (Slo1) potassium channels. FEBS Lett. 581, 1000-1008. doi: 10.1016/j.febslet.2007.01.077

Martin, G., Puig, S., Pietrzykowski, A., Zadek, P., Emery, P., and Treistman, S. (2004). Somatic localization of a specific large-conductance calcium-activated potassium channel subtype controls compartmentalized ethanol sensitivity in the nucleus accumbens. J. Neurosci. 24, 6563-6572. doi: 10.1523/JNEUROSCI. 0684-04.2004

Martire, M., Barrese, V., D’Amico, M., Iannotti, F. A., Pizzarelli, R., Samengo, I., et al. (2010). Pre-synaptic BK channels selectively control glutamate versus GABA release from cortical and hippocampal nerve terminals. J. Neurochem. 115, 411-422. doi: 10.1111/j.1471-4159.2010.06938.x 
Matthews, E. A., and Disterhoft, J. F. (2009). Blocking the BK channel impedes acquisition of trace eyeblink conditioning. Learn. Mem. 16, 106-109. doi: $10.1101 / \mathrm{lm} .1289809$

Matthews, E. A., Weible, A. P., Shah, S., and Disterhoft, J. F. (2008). The BKmediated fAHP is modulated by learning a hippocampus-dependent task. Proc. Natl. Acad. Sci. U.S.A. 105, 15154-15159. doi: 10.1073/pnas.0805855105

Misonou, H., Menegola, M., Buchwalder, L., Park, E. W., Meredith, A., Rhodes, K. J., et al. (2006). Immunolocalization of the $\mathrm{Ca} 2+$-activated $\mathrm{K}+$ channel Slo1 in axons and nerve terminals of mammalian brain and cultured neurons. J. Comp. Neurol. 496, 289-302. doi: 10.1002/cne.20931

Nelson, A. B., Krispel, C. M., Sekirnjak, C., and du Lac, S. (2003). Long-lasting increases in intrinsic excitability triggered by inhibition. Neuron 40, 609-620. doi: 10.1016/S0896-6273(03)00641-X

Poulsen, A. N., Jansen-Olesen, I., Olesen, J., and Klaerke, D. A. (2011). Neuronal fast activating and meningeal silent modulatory BK channel splice variants cloned from rat. Pflugers. Arch. 461, 65-75. doi: 10.1007/s00424-010-0887-0

Poulsen, A. N., Wulf, H., Hay-Schmidt, A., Jansen-Olesen, I., Olesen, J., and Klaerke, D. A. (2009). Differential expression of BK channel isoforms and betasubunits in rat neuro-vascular tissues. Biochim. Biophys. Acta 1788, 380-389. doi: 10.1016/j.bbamem.2008.10.001

Pratt, C. P., He, J., Wang, Y., Barth, A. L., and Bruchez, M. P. (2015). Fluorogenic green-inside red-outside (GIRO) labeling approach reveals adenylyl cyclasedependent control of BKa surface expression. Bioconjug. Chem. 26, 1963-1971. doi: 10.1021/acs.bioconjchem.5b00409

Roy, S., Large, R. J., Akande, A. M., Kshatri, A., Webb, T. I., Domene, C., et al. (2014). Development of GoSlo-SR-5-69, a potent activator of large conductance Ca2+-activated K+ (BK) channels. Eur. J. Med. Chem. 75, 426-437. doi: 10.1016/j.ejmech.2014.01.035

Roy, S., Morayo Akande, A., Large, R. J., Webb, T. I., Camarasu, C., Sergeant, G. P., et al. (2012). Structure-activity relationships of a novel group of largeconductance $\mathrm{Ca}(2+)$-activated $\mathrm{K}(+)(\mathrm{BK})$ channel modulators: the GoSlo-SR family. ChemMedChem 7, 1763-1769. doi: 10.1002/cmdc.201200321

Sakai, Y., Harvey, M., and Sokolowski, B. (2011). Identification and quantification of full-length BK channel variants in the developing mouse cochlea. J. Neurosci. Res. 89, 1747-1760. doi: 10.1002/jnr.22713

Saurabh, S., Perez, A. M., Comerci, C. J., Shapiro, L., and Moerner, W. E. (2016). Super-resolution imaging of live bacteria cells using a geneticallydirected, highly photostable fluoromodule. J. Am. Chem. Soc. 138, 10398-10401. doi: 10.1021/jacs.6b05943

Sausbier, M., Hu, H., Arntz, C., Feil, S., Kamm, S., Adelsberger, H., et al. (2004). Cerebellar ataxia and Purkinje cell dysfunction caused by Ca2+-activated $\mathrm{K}+$ channel deficiency. Proc. Natl. Acad. Sci. U.S.A. 101, 9474-9478. doi: 10.1073/ pnas.0401702101

Shipston, M. J., Duncan, R. R., Clark, A. G., Antoni, F. A., and Tian, L. (1999). Molecular components of large conductance calcium-activated potassium (BK) channels in mouse pituitary corticotropes. Mol. Endocrinol. 13, 1728-1737. doi: 10.1210/mend.13.10.0355

Shruti, S., Clem, R. L., and Barth, A. L. (2008). A seizure-induced gain-offunction in BK channels is associated with elevated firing activity in neocortical pyramidal neurons. Neurobiol. Dis. 30, 323-330. doi: 10.1016/j.nbd.2008.02.002

Shruti, S., Urban-Ciecko, J., Fitzpatrick, J. A., Brenner, R., Bruchez, M. P., and Barth, A. L. (2012). The brain-specific Beta4 subunit downregulates BK channel cell surface expression. PLOS ONE 7:e33429-e33429. doi: 10.1371/journal.pone. 0033429

Simkin, D., Cavanaugh, E. J., and Kim, D. (2008). Control of the single channel conductance of K2P10.1 (TREK-2) by the amino-terminus: role of alternative translation initiation. J. Physiol. 586, 5651-5663. doi: 10.1113/jphysiol.2008. 161927

Soom, M., Gessner, G., Heuer, H., Hoshi, T., and Heinemann, S. H. (2008). A mutually exclusive alternative exon of slo1 codes for a neuronal BK channel with altered function. Channels 2, 278-282. doi: 10.4161/chan.2.4.6571

Szent-Gyorgyi, C., Schmidt, B. A., Creeger, Y., Fisher, G. W., Zakel, K. L., Adler, S., et al. (2007). Fluorogen-activating single-chain antibodies for imaging cell surface proteins. Nat. Biotechnol. 26, 235-240. doi: 10.1038/nbt1368

Szent-Gyorgyi, C., Stanfield, R. L., Andreko, S., Dempsey, A., Ahmed, M., Capek, S., et al. (2013). Malachite green mediates homodimerization of antibody VL domains to form a fluorescent ternary complex with singular symmetric interfaces. J. Mol. Biol. 425, 4595-4613. doi: 10.1016/j.jmb.2013.08.014
Tabarki, B., AlMajhad, N., AlHashem, A., Shaheen, R., and Alkuraya, F. S. (2016). Homozygous KCNMA1 mutation as a cause of cerebellar atrophy, developmental delay and seizures. Hum. Genet. 135, 1295-1298. doi: 10.1007/ s00439-016-1726-y

Tian, L., Coghill, L. S., MacDonald, S. H.-F., Armstrong, D. L., and Shipston, M. J. (2003). Leucine zipper domain targets cAMP-dependent protein kinase to mammalian BK channels. J. Biol. Chem. 278, 8669-8677. doi: 10.1074/jbc. M211661200

Toro, B., Cox, N., Wilson, R. J., Garrido-Sanabria, E., Stefani, E., Toro, L., et al. (2006). KCNMB1 regulates surface expression of a voltage and Ca2+-activated $\mathrm{K}+$ channel via endocytic trafficking signals. Neuroscience 142, 661-669. doi: 10.1016/j.neuroscience.2006.06.061

Toro, L., Li, M., Zhang, Z., Singh, H., Wu, Y., and Stefani, E. (2013). MaxiK channel and cell signalling. Pflüg. Arch. 466, 875-886. doi: 10.1007/s00424-013-1359-0

Toro, L., Wallner, M., Meera, P., and Tanaka, Y. (1998). Maxi-KCa, a unique member of the voltage-gated K channel superfamily. Physiology 13, 112-117.

Tseng-Crank, J., Foster, C. D., Krause, J. D., Mertz, R., Godinot, N., DiChiara, T. J., et al. (1994). Cloning, expression, and distribution of functionally distinct $\mathrm{Ca}(2+)$-activated $\mathrm{K}+$ channel isoforms from human brain. Neuron 13, 1315-1330. doi: 10.1016/0896-6273(94)90418-9

van Welie, I., and du Lac, S. (2011). Bidirectional control of BK channel open probability by CAMKII and PKC in medial vestibular nucleus neurons. J. Neurophysiol. 105, 1651-1659. doi: 10.1152/jn.00058.2011

Vergara, C., Latorre, R., Marrion, N. V., and Adelman, J. P. (1998). Calciumactivated potassium channels. Curr. Opin. Neurobiol. 8, 321-329. doi: 10.1016/ S0959-4388(98)80056-1

Wallner, M., Meera, P., and Toro, L. (1996). Determinant for beta-subunit regulation in high-conductance voltage-activated and $\mathrm{Ca}(2+)$-sensitive $\mathrm{K}+$ channels: an additional transmembrane region at the $\mathrm{N}$ terminus. Proc. Natl. Acad. Sci. U.S.A. 93, 14922-14927. doi: 10.1073/pnas.93.25.14922

Wang, B., Bugay, V., Ling, L., Chuang, H.-H., Jaffe, D. B., and Brenner, R. (2016). Knockout of the BK $\beta 4$ subunit promotes a functional coupling of BK channels and ryanodine receptors that mediate a fAHP-induced increase in excitability. J. Neurophysiol. 116, 456-465. doi: 10.1152/jn.00857.2015

Wang, Y., Ballou, B., Schmidt, B. F., Andreko, S., St Croix, C. M., Watkins, S. C., et al. (2017). Affibody-targeted fluorogen activating protein for in vivo tumor imaging. Chem. Commun. Camb. Engl. 53, 2001-2004. doi: 10.1039/c6cc09137g

Wang, Y., Telmer, C. A., Schmidt, B. F., Franke, J. D., Ort, S., Arndt-Jovin, D. J., et al. (2015). Fluorogen activating protein-affibody probes: modular, nowash measurement of epidermal growth factor receptors. Bioconjug. Chem. 26, 137-144. doi: 10.1021/bc500525b

Wang, Z. (2008). Regulation of synaptic transmission by presynaptic CaMKII and BK channels. Mol. Neurobiol. 38, 153-166. doi: 10.1007/s12035-008-8039-7. Regulation

Webb, T. I., Kshatri, A. S., Large, R. J., Akande, A. M., Roy, S., Sergeant, G. P., et al. (2015). Molecular mechanisms underlying the effect of the novel BK channel opener GoSlo: involvement of the S4/S5 linker and the S6 segment. Proc. Natl. Acad. Sci. U.S.A. 112, 2064-2069. doi: 10.1073/pnas.1400555112

Wen, D., Cornelius, R. J., Yuan, Y., and Sansom, S. C. (2013). Regulation of BKexpression in the distal nephron by aldosterone and urine pH. AJP Ren. Physiol. 305, F463-F476. doi: 10.1152/ajprenal.00171.2013

Wynne, P. M., Puig, S. I., Martin, G. E., and Treistman, S. N. (2009). Compartmentalized subunit distribution determines characteristics and ethanol sensitivity of somatic, dendritic, and terminal large-conductance calcium-activated potassium channels in the rat central nervous system. J. Pharmacol. Exp. Ther. 329, 978-986. doi: 10.1124/jpet.108. 146175

Yan, Q., Schmidt, B. F., Perkins, L. A., Naganbabu, M., Saurabh, S., Andreko, S. K., et al. (2015). Near-instant surface-selective fluorogenic protein quantification using sulfonated triarylmethane dyes and fluorogen activating proteins. Org. Biomol. Chem. 13, 2078-2086. doi: 10.1039/C4OB02309A

Zarei, M. M., Song, M., Wilson, R. J., Cox, N., Colom, L. V., Knaus, H. G., et al. (2007). Endocytic trafficking signals in KCNMB2 regulate surface expression of a large conductance voltage and Ca2+-activated K+ channel. Neuroscience 147, 80-89. doi: 10.1016/j.neuroscience.2007.04.019

Zhang, M., Chakraborty, S. K., Sampath, P., Rojas, J. J., Hou, W., Saurabh, S., et al. (2015). Fluoromodule-based reporter/probes designed for in vivo fluorescence imaging. J. Clin. Invest. 125, 3915-3927. doi: 10.1172/JCI81086 
Zhang, Z.-B., Tian, M.-Q., Gao, K., Jiang, Y.-W., and Wu, Y. (2015). De novo KCNMA1 mutations in children with early-onset paroxysmal dyskinesia and developmental delay. Mov. Disord. 30, 1290-1292. doi: 10.1002/mds.26216

Conflict of Interest Statement: MB is a founder in Sharp Edge Labs, Inc., a company exploiting the FAP-Fluorogen tagging for drug discovery.

The other authors declare that the research was conducted in the absence of any commercial or financial relationships that could be construed as a potential conflict of interest.
The reviewer CC declared a past co-authorship with one of the authors $\mathrm{AB}$ to the handling Editor.

Copyright () 2017 Pratt, Kuljis, Homanics, He, Kolodieznyi, Dudem, Hollywood, Barth and Bruchez. This is an open-access article distributed under the terms of the Creative Commons Attribution License (CC BY). The use, distribution or reproduction in other forums is permitted, provided the original author(s) or licensor are credited and that the original publication in this journal is cited, in accordance with accepted academic practice. No use, distribution or reproduction is permitted which does not comply with these terms. 